\title{
Crystallization Kinetics of Amorphous Materials
}

\author{
Miray Çelikbilek, Ali Erçin Ersundu and Süheyla Aydın \\ Istanbul Technical University \\ Turkey
}

\section{Introduction}

Amorphous (non-crystalline) materials have no crystal structure where the atoms appear to have a random distribution (Omar, 1993). There are different classes of amorphous materials. Glasses, inorganic materials which have no long-range order $(<10 \AA)$ and high viscosity greater than 1013 Poise, are the most typical amorphous materials (Doremus, 1973; Jackson, 2004; Park, 2009). The regular arrangement resulting from the distribution over long distances of a repeating atomic arrangement, which is characteristic of a crystal, is missing in glasses (see Fig. 1). However, there is often evidence of a short-range order in glasses, which corresponds to the atomic arrangement in the immediate vicinity of any selected atom (Carter \& Norton, 2007).

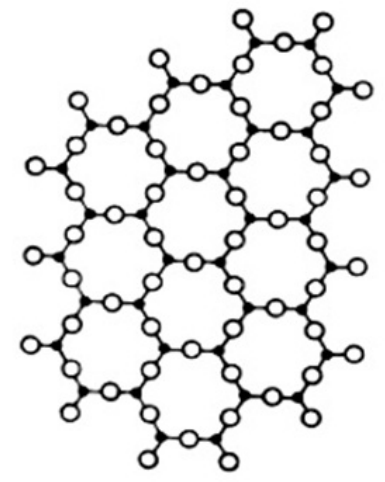

(a)

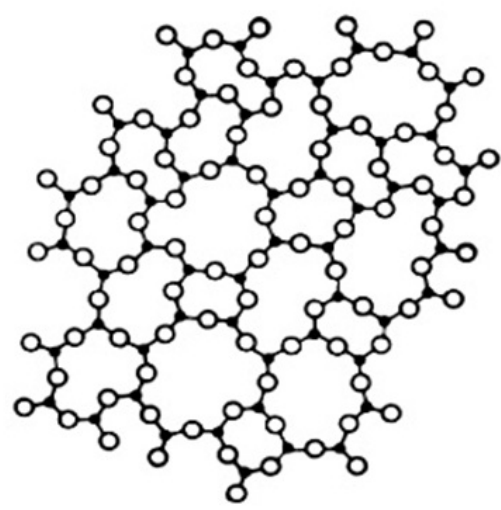

(b)

Fig. 1. Schematic two-dimensional illustration of the atomic arrangement in (a) crystal and (b) glass (Carter \& Norton, 2007)

Glass can be formed by cooling from a liquid state without a change in its specific volume, which delays crystallization and assist to reach the glass transition temperature before the crystallization occurs (Jackson, 2004; Park, 2009). This is why amorphous materials, such as glasses, are sometimes referred to as supercooled liquids (Omar, 1993).

In a liquid, the atoms or molecules move around much more rapidly than in a crystal. They are constantly in motion, jiggling around relative to each other, unlike in a crystal, where the 
atoms are bound to specific lattice sites. When a liquid is cooled, the space for the atoms to move around decreases and on further cooling below the glass transition temperature, the atoms can no longer move around with respect to each other, and so the material becomes a solid. A measure of this is the specific volume, which can be measured as the difference between the density of the crystal and of the liquid. As a glass-forming material cools, this excess volume decreases, and finally the density of the glass approaches that of the crystal, as illustrated in Fig. 2. In practice, the formation of an amorphous or crystalline solid depends on how rapidly the liquid is cooled through the glass transition temperature (Jackson, 2004). Upon cooling the liquid, if there is a discontinuity in volume change or in rate of cooling the liquid crystallizes, however if the liquid passes into a supercooled state the volume decreases and no crystallization occurs (Carter \& Norton, 2007).

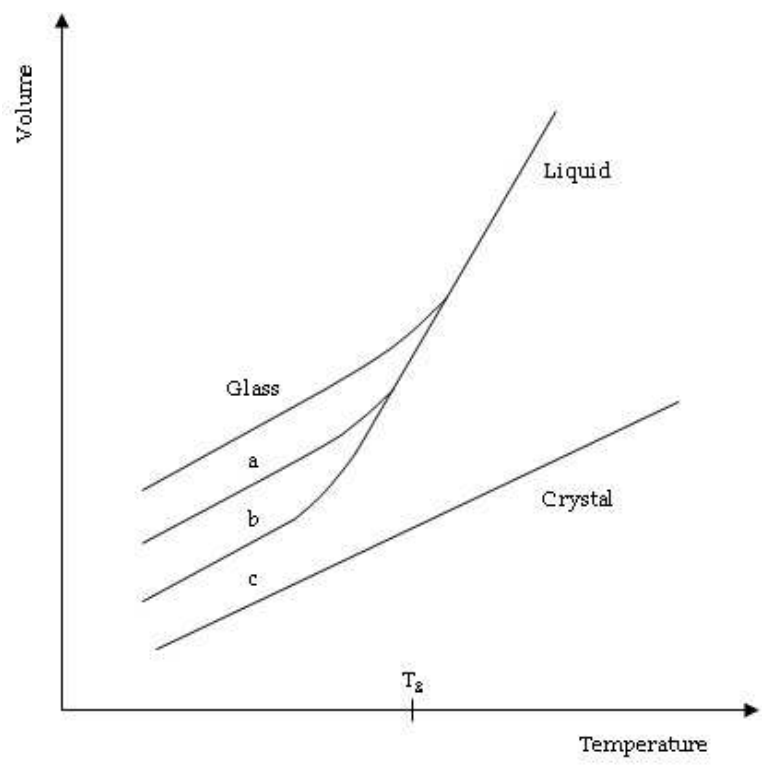

Fig. 2. The specific volume in a liquid decreases more rapidly with temperature than the crystal. The thermal expansion coefficient of glass is similar to that of the crystal. The final specific volume of the glass depends on the cooling rate: (a) fast cooling, (b) normal cooling, (c) slow cooling (Carter \& Norton, 2007; Jackson, 2004)

It is believed that most materials can be prepared as glasses by sufficiently rapid quenching but there is a notable exception: no pure metal has been prepared in an amorphous state (Jackson, 2004). Materials which can form non-crystalline solids with the atomic arrangement shown in Fig. $1 \mathrm{~b}$ and at an appreciable size are found in glass systems in oxides, halides, and chalcogenides. The three-dimensional random network of strong bonds is developed by the constituent called the "network former". In principle, glass formation is possible for a system of any composition provided if it contains sufficient of the network former. Network modifiers can also participate in glass formation by acting to modify the glass properties. These components do not form networks but occupy thermodynamically stable sites as illustrated schematically in Fig. 3 or act as a replacement for a part of network 
former. Among various oxides used in the industrial materials, $\mathrm{SiO}_{2}, \mathrm{GeO}_{2}, \mathrm{~B}_{2} \mathrm{O}_{3}$, and $\mathrm{P}_{2} \mathrm{O}_{5}$ are known to be good network formers which can develop the three-dimensional random network and can form a glass by themselves (Yamane \& Ashara, 2000).

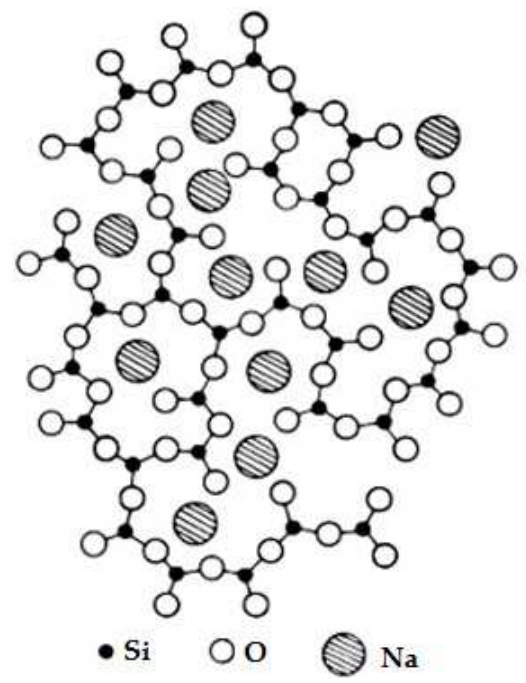

Fig. 3. Schematic two-dimensional illustration of the structure of a binary sodium silicate glass (Yamane \& Ashara, 2000)

The special glasses used as key components of various devices in the fields of optics, electronics, and opto-electronics are not always silicates but are often non-silicate glasses of the phosphate, borate, germanate, vanadate or tellurite systems. Although non-silicate glasses are not generally applied to mass production due to the high cost of raw materials and their rather inferior chemical durability, they do show unique properties that cannot be obtained for silicate glasses (Yamane \& Ashara, 2000). Comparing with silicate, borate and phosphate glasses, tellurite glasses have drawn considerable attention because of their various promising properties, such as relatively low-phonon energy, high linear and nonlinear refractive index, high dielectric constant, good infrared transmission, good corrosion resistance, thermal and chemical stability, low crystallization ability and easy fabrication at low temperatures. Therefore, tellurite glasses are of scientifically and technologically important for their potential use in fiber optics, laser hosts, infrared and infrared to visible upconversion applications in optical data storage, sensors, and spectroscopic applications. $\mathrm{TeO}_{2}$ is a conditional glass former which does not transform to the glassy state under normal quenching conditions. Therefore, addition of a secondary component, such as heavy metal oxides, alkalis or halogens increases its glass forming ability (Çelikbilek et al., 2010, 2011a, 2011b; El-Mallawany, 2002; Ersundu et al., 2010a, 2010b, 2011; Karaduman et al., 2011).

In order to use special glasses in the fields of opto-electronics at high optical intensities without exposure to thermal damage it is important to recognize their physical and thermal characteristics and also to control the crystallization processes. The investigation of crystallization in terms of kinetics is an important informational tool for the audience and 
therefore this chapter "Crystallization Kinetics of Amorphous Materials" is crucial to have a complete understanding of the crystallization phenomenon.

\section{Crystallization}

Crystallization of a liquid or an amorphous solid is a complex process involving simultaneous nucleation and growth of crystallites (Yinnon \& Uhlmann, 1983). Crystallization is initiated by crystal nucleation. Nucleation may occur spontaneously or it may be induced artificially. It is not always possible, however, to decide whether a system has nucleated of its own accord or whether it has done so under the influence of some external stimulus (Mullin, 2001). The nucleation either occurs without the involvement of a foreign substance in the interior of the parent phase which is called "homogeneous or primary nucleation" or with the contact of the parent phase with a foreign substance that acts as a preferred nucleation site which is called "heterogeneous or secondary nucleation". The nucleation process is followed by the growth of the crystal nuclei to macroscopic dimensions, which is called "crystal growth" (Kalb, 2009).

\subsection{Homogeneous nucleation}

Homogeneous nucleation occurs in the interior of the parent phase without the involvement of a foreign substance. At temperatures below a material's melting point $\left(T_{\mathrm{m}}\right)$, the driving force for solidification is the difference in Gibbs free energy $(\Delta G)$ between the liquid and the solid. If we assume that the heat capacities of the liquid and solid are equal, then the molar enthalpy and molar entropy of solidification will each remain constant as a function of temperature, and $\Delta G$ can be calculated as follows:

$$
\begin{aligned}
& \text { liquid } \rightarrow \text { solid } \\
& \Delta G=\Delta H-T \Delta S
\end{aligned}
$$

Note that $\Delta H=-L$, where $L$ is the latent heat of fusion.

$$
\begin{gathered}
\Delta G=-L+T \frac{L}{T_{\mathrm{m}}} \\
\Delta G=\frac{L}{T_{\mathrm{m}}}\left(T-T_{\mathrm{m}}\right)
\end{gathered}
$$

When a spherical particle of solid of radius $r$ is formed, the change in Gibbs free energy is the volume of the particle multiplied by the volumetric Gibbs free energy change, $\Delta G_{v}$.

$$
\Delta G_{\mathrm{vol}}=\frac{4}{3} \Pi r^{3} \Delta G_{\mathrm{v}}
$$

where $\Delta G_{v}$ is the Gibbs free energy per unit volume,

$$
\begin{gathered}
\Delta G_{\mathrm{v}}=\frac{1}{V} \frac{L}{T_{\mathrm{m}}}\left(T-T_{\mathrm{m}}\right) \\
\Delta \mathrm{G}_{\mathrm{vol}}=\frac{4}{3} \Pi \mathrm{r}^{3} \frac{1}{\mathrm{~V}} \frac{\mathrm{L}}{\mathrm{T}_{\mathrm{m}}}\left(\mathrm{T}-\mathrm{T}_{\mathrm{m}}\right)
\end{gathered}
$$


But when the particle of radius $r$ is formed, there is another energy term to be considered, the surface energy. The surface energy of the particle is:

$$
\Delta G_{S}=4 \Pi r^{2} \gamma
$$

where $\gamma=\gamma_{s-1}$ the surface energy between solid and liquid.

The sum of the two energy term is:

$$
\Delta G_{\mathrm{r}}=4 \Pi r^{2} \gamma+\frac{4}{3} \Pi r^{3} \Delta G_{\mathrm{v}}
$$

The first of these terms involves the increase in energy required to form a new surface. The second term is negative and represents the decrease in Gibbs free energy upon solidification. Because the first is a function of the second power of the radius, and the second a function of the third power of the radius, the sum of the two increases, goes through a maximum, and then decreases (Fig. 4).

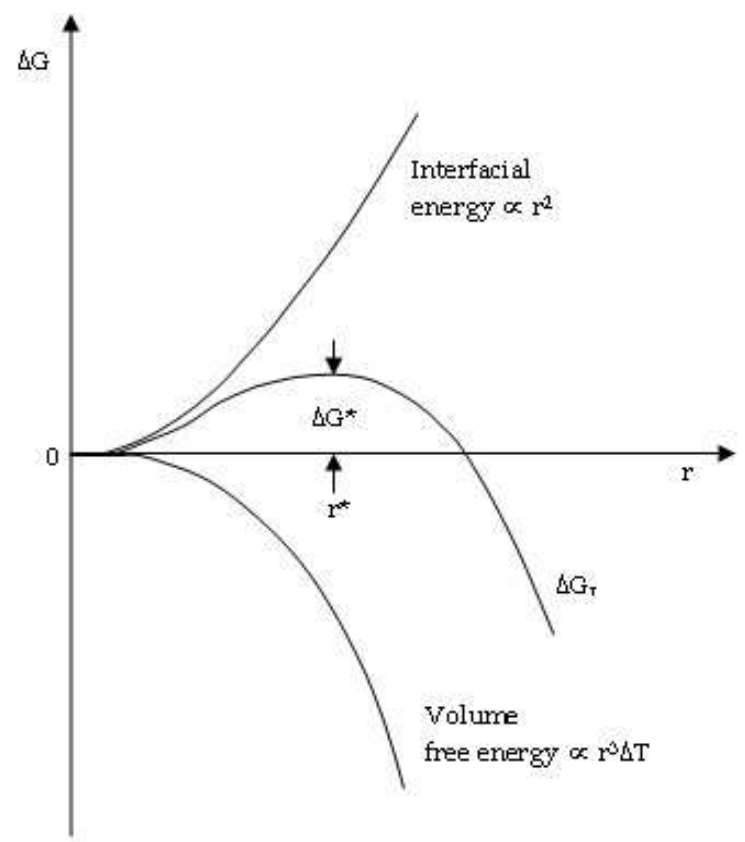

Fig. 4. The free energy change associated with homogeneous nucleation of a sphere of radius $r$ (Ragone, 1994)

The radius at which the Gibbs free energy curve is at maximum is called the critical radius $r^{*}$, for a nucleus of solid in liquid. The driving force of the Gibbs free energy will tend to cause a particle with a smaller radius than $r^{*}$ to decrease in size. This is a particle of subcritical size for nucleation. A viable nucleus is one with radius greater than or equal to $r^{*}$. The critical Gibbs free energy corresponding to the radius $r^{*}$ is $\Delta G^{*}$. These terms can be shown to be: 


$$
\begin{aligned}
r^{*} \text { when }\left(\frac{\partial \Delta G_{\mathrm{r}}}{\partial r}\right)_{T} & =0=8 \Pi r \gamma+4 \Pi r^{2} \Delta G_{\mathrm{V}} \\
r^{*} & =-\frac{2 \gamma}{\Delta G_{\mathrm{v}}} \\
\Delta G^{*} & =\frac{16}{3} \frac{\Pi \gamma^{3}}{\Delta G_{\mathrm{v}}^{2}}
\end{aligned}
$$

In practice homogeneous nucleation is rarely encountered in solidification. Instead heterogeneous nucleation occurs at crevices in mould walls, or at impurity particles suspended in the liquid.

\subsection{Heterogeneous nucleation}

Usually, foreign phases like container walls and impurities aid in the nucleation process and thereby increase the nucleation rate. In this case, nucleation is called heterogeneous (Kalb, 2009).

Under practical solidification conditions, supercooling of only a few degrees is observed because nuclei of the solid can be formed on surfaces that catalyze solidification, such as inclusions in the material being solidified, the walls of the container in which it is being held, or the surfaces of the casting molds. To catalyze solidification, the nucleus of solid must wet the catalyst to some extent. A nucleus catalyzed on a surface is shown schematically in Fig. 5.
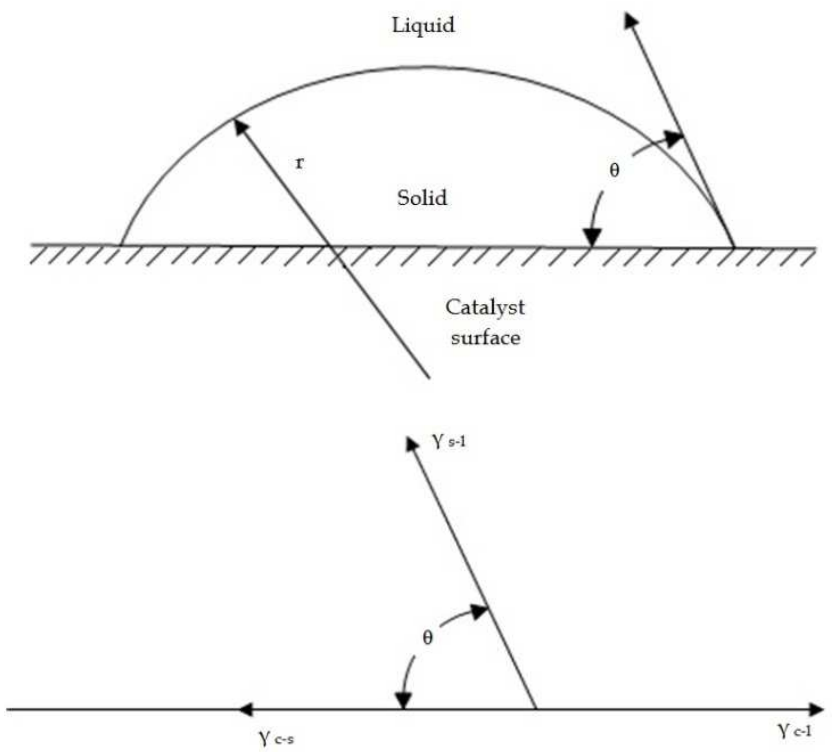

Fig. 5. Catalysis of a nucleus on a surface (Porter \& Easterling, 1992)

The analysis of the energies involved in heterogeneous nucleation follows the same method as the one used for homogeneous nucleation. In the case of a heterogeneous nucleus in the 
form of a spherical cap (Fig. 5), the surface energy term involves the surface energy of the catalyst surface as it is coated by the nucleus.

The surface energy term is derived as follows:

solid-liquid surface $=2 \pi r^{2}(1-\cos \theta)$

catalyst-solid surface $=\Pi r^{2}\left(1-\cos ^{2} \theta\right)$

where $r$ is the radius of the curvature of the nucleus. Then we write

$$
\Delta G_{\text {surface }}=2 \Pi r^{2}(1-\cos \theta) \gamma_{\mathrm{s}-1}+\Pi r^{2}\left(1-\cos ^{2} \theta\right)\left(\gamma_{\mathrm{c}-\mathrm{s}}-\gamma_{\mathrm{c}-1}\right)
$$

where $\quad \gamma_{\mathrm{s}-1}=$ solid-liquid interfacial energy

$\gamma_{\mathrm{c}-\mathrm{s}}=$ solid-catalyst interfacial energy

$\gamma_{\mathrm{c}-\mathrm{I}}=$ liquid-catalyst interfacial energy

The terms involving the interactions between the catalyst surface and the liquid and solid can be expressed in terms of the solid-liquid interfacial energy by noting the relationships among them.

$$
\gamma_{c-1}=\gamma_{c-s}+\gamma_{s-1}(\cos \theta)
$$

The volumetric Gibbs free energy change is the product of the volume of the cap and $\Delta G_{\mathrm{v}}$, the specific Gibbs free energy change. That volume, in terms of its radius of the curvature and contact angle is:

$$
\mathrm{V}=\frac{4}{3} \Pi r^{3}\left\{\frac{(2+\cos \theta)(1-\cos \theta)^{2}}{4}\right\}
$$

or

$$
\Delta G_{\mathrm{vol}}=\frac{4}{3} \Pi r^{3} \Delta G_{\mathrm{v}} f(\theta)
$$

where

$$
\begin{gathered}
f(\theta)=\left\{\frac{(2+\cos \theta)(1-\cos \theta)^{2}}{4}\right\} \\
r^{*}=-\frac{2 \gamma_{\mathrm{s}-1}}{\Delta G_{\mathrm{v}}} \\
\Delta G^{*}=\frac{16}{3} \frac{\pi \gamma_{\mathrm{s}-1}^{3}}{\Delta G_{\mathrm{v}}^{2}} f(\theta)
\end{gathered}
$$

It is particularly important to note that the critical radius of curvature, $r^{*}$, does not change when the nucleation becomes heterogeneous. The critical Gibbs free energy, $\Delta G^{*}$, however, is strongly influenced by the wetting that occurs at the surface of the material that catalyzes the nucleation. A lower values of $\Delta G^{*}$ means a lower activation energy to be overcome in nucleation; that is, nucleation takes place more easily. The magnitude of the effect can be appreciated by considering values of $f(\theta)$. $f(\theta)$ is the ratio of the volume of the heterogeneous nucleus (the cap) to the volume of the sphere with the same radius of curvature (Ragone, 1994). 
Fig. 6, a graph of $\Delta G$ as a function of radius of curvature of the nucleus, shows the effect of wetting on the critical Gibbs free energy to be overcome for the nucleus to form.

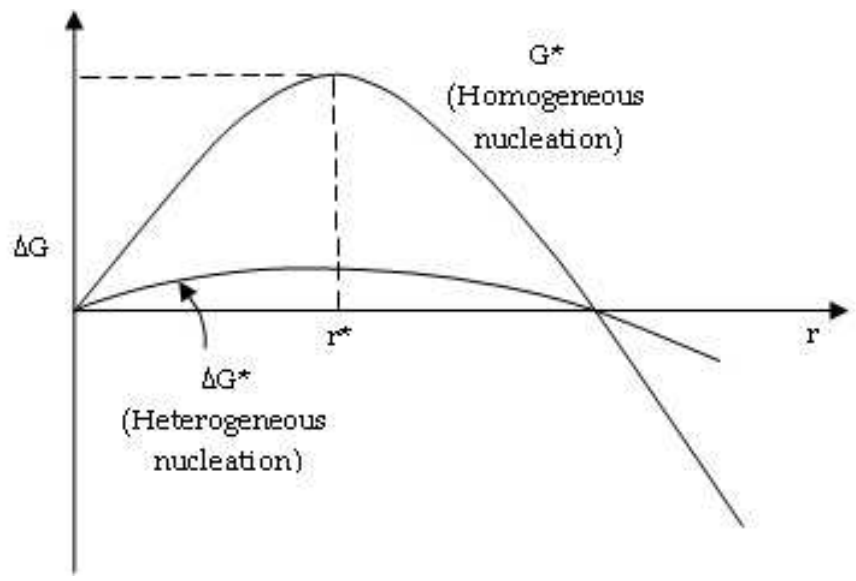

Fig. 6. Plot of $\Delta G$ versus $r$ for homogeneous nucleation and an example of heterogeneous nucleation (Ragone, 1994)

The critical Gibbs free energy for nucleation depends on the nucleus volume. This can be demonstrated by considering a nucleus having the shape of spherical cap with radius of curvature $r$. The Gibbs free energy of the nucleus depends on the interfacial energy and the volumetric Gibbs free energy change as follows:

$$
\Delta G_{\mathrm{r}}=\alpha r^{2} \gamma^{+} \beta r^{3} \Delta G_{\mathrm{v}}
$$

The parameters $\alpha$ and $\beta$ are determined by the particular geometry of the nucleus. The surface energy term, $\gamma$, is an average surface energy for the nucleus determined according to the geometrical factors.

The volume of the nucleus is $\beta r^{3}$. To determine $r^{*}$,

$$
\begin{gathered}
\left(\frac{\partial \Delta \mathrm{G}_{\mathrm{r}}}{\partial \mathrm{r}}\right)_{\mathrm{T}}=0 \\
2 a \gamma r^{*}+3 \beta r^{* 2} \Delta G_{\mathrm{V}}=0 \\
r^{*}=-\frac{2 \alpha}{3 \beta \Delta G_{\mathrm{V}}} \gamma \text { or } \alpha=-\frac{3 \beta \Delta G_{\mathrm{V}}}{2 \gamma} r^{*}
\end{gathered}
$$

Substituting in Equation 19, we have

$$
\begin{gathered}
\Delta G_{\mathrm{r}}^{*}=-\frac{3 \beta \Delta G_{\mathrm{v}} r^{*}}{2}\left(r^{*}\right)^{2}+\Delta G_{\mathrm{V}} \beta\left(r^{*}\right)^{3} \\
\Delta G_{\mathrm{r}}^{*}=-\frac{1}{2} \beta\left(r^{*}\right)^{3} \Delta G_{\mathrm{V}} \\
\Delta G_{\mathrm{r}}^{*}=-\frac{1}{2} V^{*} \Delta G_{\mathrm{V}}
\end{gathered}
$$


where $V^{*}$ is the volume of the critical nucleus.

It is apparent that any factors that reduce the volume of the nucleus reduce the critical Gibbs free energy of formation of that nucleus, making nucleation more probable (Ragone, 1994).

The activation energy barrier against heterogeneous nucleation $\left(\Delta G^{*}\right.$ het $)$ is smaller than $\Delta G^{*}$ hom by the shape factor $f(\theta)$. In addition, the critical nucleus radius $\left(r^{*}\right)$ is unaffected by the mould wall and only depends on the undercooling. This result was to be expected since equilibrium across the curved interface is unaffected by the presence of the mould wall.

The effect of undercooling on $\Delta G^{*}$ het and $\Delta G^{*}$ hom is shown schematically in Fig. 7a. If there are $n$ atoms in contact with the mould wall the number of nuclei should be given by:

$$
n^{*}=n_{1} \exp \left(-\frac{\Delta G_{\text {het }}^{*}}{k T}\right)
$$

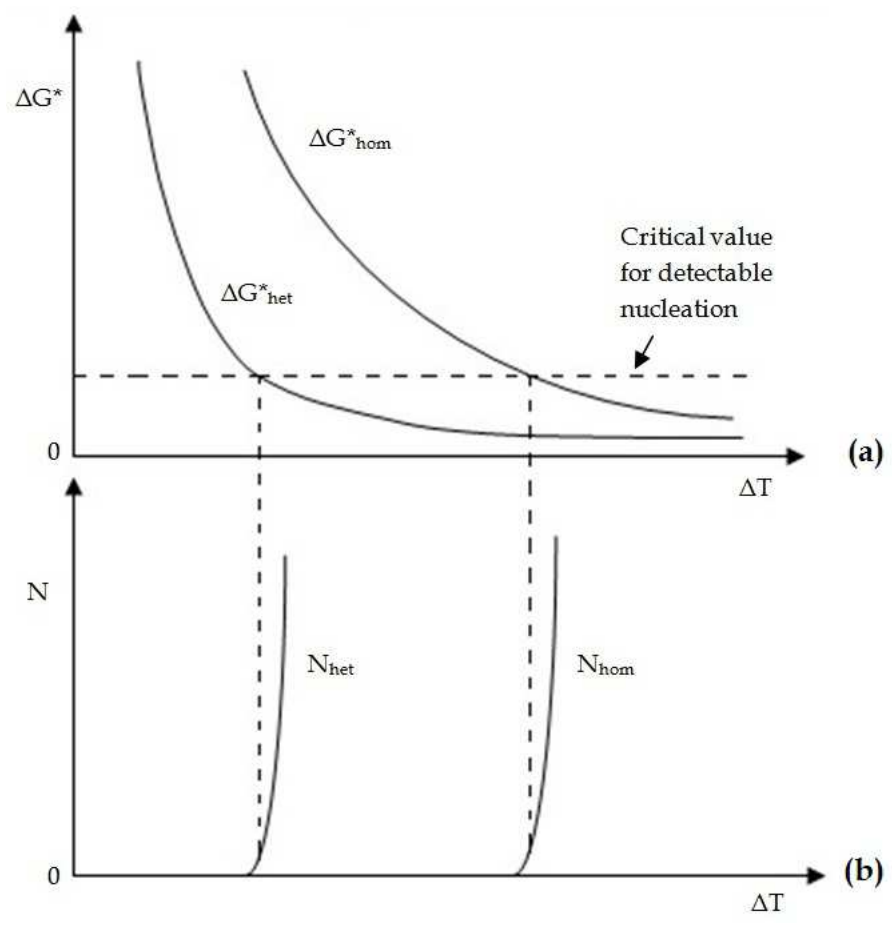

Fig. 7. (a) Variation of $\Delta G^{*}$ with undercooling $(\Delta T)$ for homogeneous and heterogeneous nucleation, (b) The corresponding nucleation rates assuming the same critical value of $\Delta G^{*}$ (Porter \& Easterling, 1992)

Therefore, heterogeneous nucleation should become feasible when $\Delta G^{*}$ het becomes sufficiently small. The critical value for $\Delta G^{*}$ het should not be very different from the critical value for homogeneous nucleation. It will mainly depend on the magnitude of $n_{1}$, in Equation 26. It can be seen from Fig. $7 \mathrm{~b}$ that heterogeneous nucleation will be possible at much lower undercoolings than are necessary for homogeneous nucleation. 


\subsection{Growth}

Nucleation is the birth of new crystal nuclei either spontaneously from solution or in the presence of existing crystals. Crystal growth is the increase in size of crystals as solute is deposited from solution. These often competing mechanisms ultimately determine the final crystal size distribution. The rate of growth of a transformation product is determined by the driving force for the transformation and the frequency with which molecules successfully make the transition from the reactant phase to the product phase. To use solidification as an example, the driving force is the negative of the $\Delta G$ of solidification:

$$
-\Delta G=\frac{L}{T_{\mathrm{m}}}\left(T_{\mathrm{m}}-T\right)
$$

The jump frequency across the liquid-solid interface has a temperature dependence of the form:

$$
f=f_{0} \exp \left(-\frac{\Delta G_{M}}{k T}\right)
$$

where $\Delta G_{M}$ is the activation energy for movement across the liquid-solid interface. The product of the two is:

$$
\text { solidification rate }=f_{0} \exp \left(-\frac{\Delta G_{\mathrm{M}}}{k T}\right)\left(\frac{L}{T_{\mathrm{m}}}\right)\left(T_{\mathrm{m}}-T\right)
$$

As the temperature decreases, the driving force increases but the jump frequency decreases. These two opposing dependencies can produce a maximum in the rate of growth as a function of temperature, as illustrated in Fig. 8.

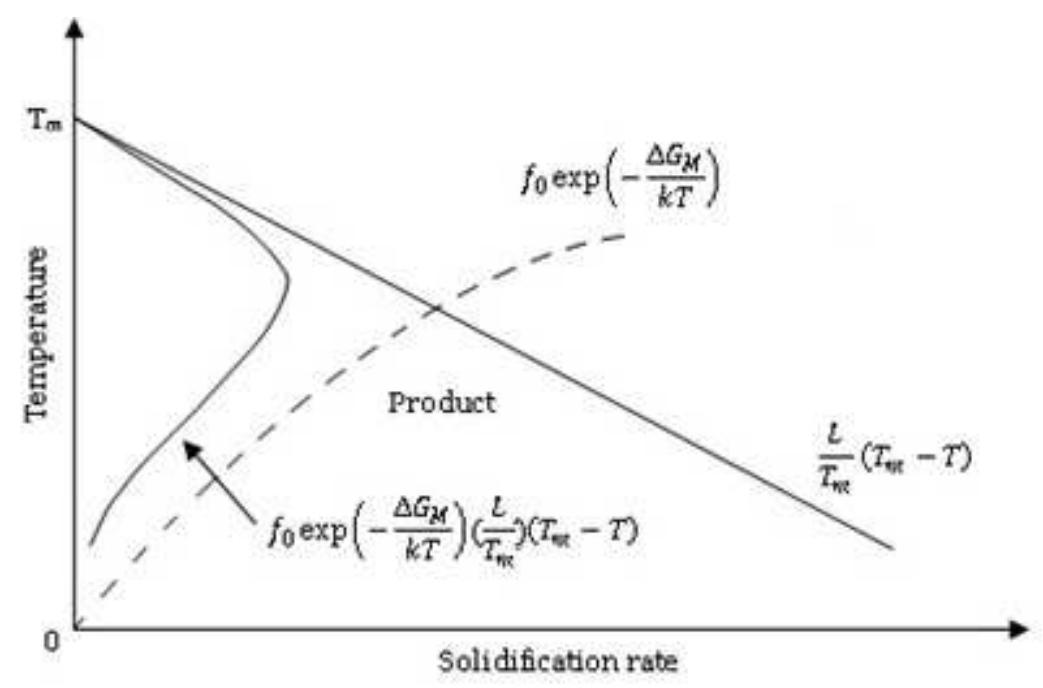

Fig. 8. Solidification rate as a function of temperature (Ragone, 1994)

The temperature dependencies of both nucleation of a new phase and its rate of growth result in a strong temperature dependence of transformation rate. 


\subsection{Supersaturation}

Supersaturation is the difference between the actual concentration and the solubility concentration at a given temperature which is the driving force for all solution crystallization processes. The figure below (Fig. 9) illustrates the concept of supersaturation and introduces the metastable zone width (MSZW), the kinetic boundary at which crystallization occurs (Porter \& Easterling, 1992).

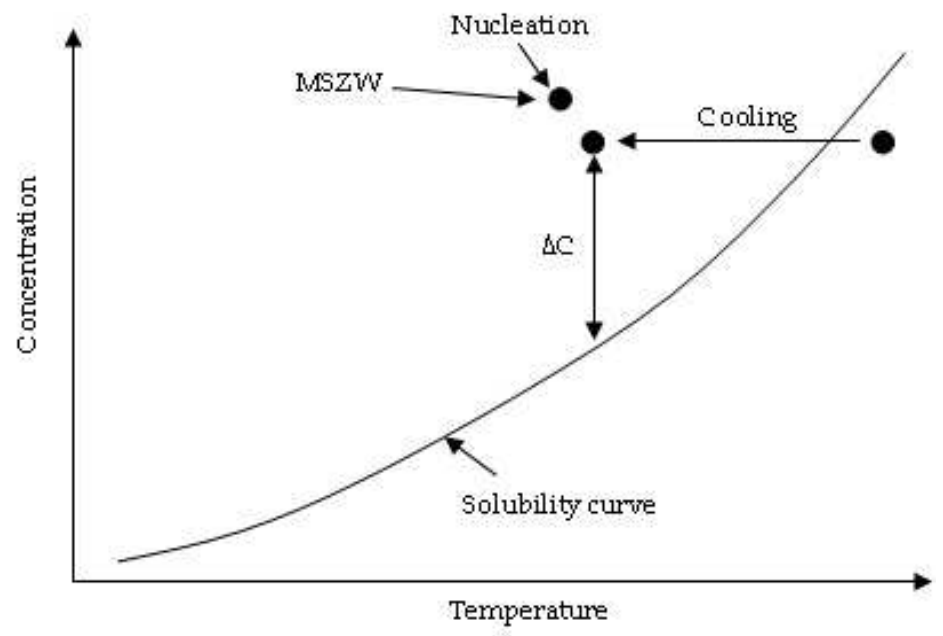

Fig. 9. The excess free energy of solid clusters for homogeneous and heterogeneous nucleation. Note $r^{*}$ is independent of nucleation site

Supersaturation is critical because it is the driving force for crystal nucleation and growth. The relationship between supersaturation and nucleation and growth is defined by the following equations.

$$
\begin{aligned}
G & =k_{\mathrm{g}} \Delta C^{\mathrm{g}} \\
B & =k_{\mathrm{b}} \Delta C^{\mathrm{b}}
\end{aligned}
$$

where, $G$ is growth rate, $k_{\mathrm{g}}$ is growth constant, $g$ is growth order, $B$ is nucleation rate, $k_{\mathrm{b}}$ is nucleation constant, $\mathrm{b}$ is nucleation order, $\Delta C$ is supersaturation.

At low supersaturation, crystals can grow faster than they nucleate resulting in a larger crystal size distribution. However, at higher supersaturation, crystal nucleation dominates crystal growth, ultimately resulting in smaller crystals. This diagram, relating supersaturation to nucleation, growth and crystal size clearly illustrates how controlling supersaturation is vitally important when it comes to creating crystals of the desired size and specification (see Fig. 10) (Porter \& Easterling, 1992).

The rate of crystal nucleation in glasses reaches its maximum at a temperature somewhat higher than the glass transition temperature and then decreases rapidly with increasing temperature, while the rate of crystal growth reaches its maximum at a temperature much 
higher than the temperature at which the nucleation rate is highest. Therefore, when a glass is heated at a constant rate, crystal nuclei are formed at lower temperature and grow in size at higher temperatures without any increase in number (Matusita \& Sakka, 1981).

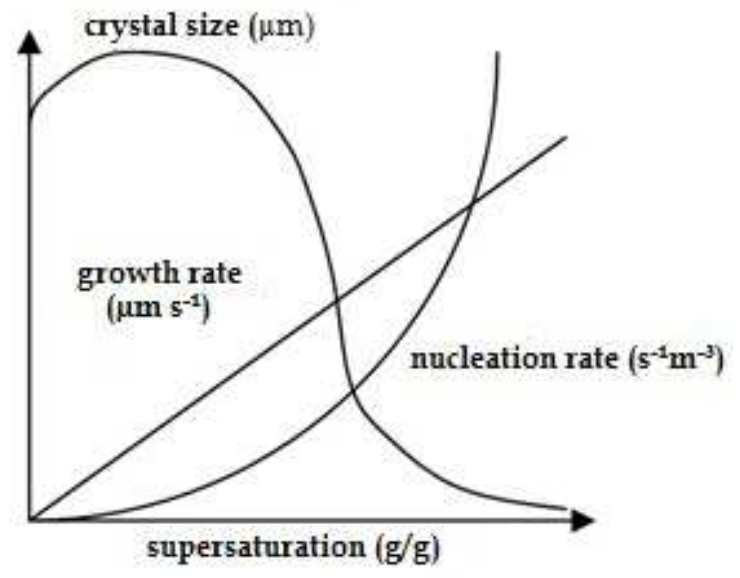

Fig. 10. The relationship between supersaturation and nucleation and growth

\section{Kinetic investigation of crystallization}

The theory of crystallization in amorphous materials can be explained by considering the structure and the kinetics of the crystallization. Therefore, the investigation of crystallization kinetics is important since it quantifies the effect of the nucleation and growth rate of the resulting crystallites (Carter \& Norton, 2007; Kashchiev, 2000). In this chapter, crystallization kinetics of amorphous materials was investigated by explaining the crystallization mechanism and the crystallization activation energy in terms of isothermal and nonisothermal methods with different approaches. Different thermal analysis techniques used in crystallization kinetic studies were presented and a correlation between kinetic and structural investigations was made to determine the crystallization mechanism (Araújo \& Idalgo, 2009; Malek, 2000; Prasad \& Varma, 2005).

The crystallization kinetics of amorphous materials can be investigated either isothermally or non-isothermally by using thermal analysis techniques. In the isothermal method, the sample is heated above the glass transition temperature and the heat absorbed during the crystallization process is measured as a function of time. On the other hand, in the nonisothermal method, the sample is heated at a fixed rate and then the change in enthalpy is recorded as a function of temperature. Thermal analysis techniques such as differential thermal analysis (DTA) and differential scanning calorimetry (DSC) are quite popular for kinetic analysis of crystallization processes in amorphous solids (Araújo \& Idalgo, 2009; Malek, 2000; Prasad \& Varma, 2005).

Many of the reactions of interest to materials scientists involve transformations in the solid state, reactions such as recrystallization of a cold-worked material, the precipitation of a crystalline polymer from an amorphous phase, or the growth of an equilibrium phase from 
a non-equilibrium structure, the driving force for which is brought about by cooling from one temperature to another. Consider the initial phase to be a and the resulting phase to be $\beta$; the reaction is written:

$$
a \rightarrow \beta
$$

The total volume of the sample is the sum of the volumes of $\alpha$ and $\beta$ :

$$
V=V^{\alpha}+V^{\beta}
$$

The fraction transformed can be represented in the literature as $x, \mathrm{a}$ or $\mathrm{F}$ :

$$
x=\frac{V^{\beta}}{V}
$$

Assume that the transformation from a to $\beta$ is controlled by nucleation and growth, that is, the nucleation of phase $\beta$ within $\alpha$ and then the rate of growth of $\beta$.

If we consider $N$ is the nucleation rate per unit volume and $G$ is the growth rate in one direction $=d r / d t$ (assuming spherical form of $\beta$ ). Consider the time line from zero to a time, $t$ (see Fig. 11). We will consider another measure of time $(\tau)$, which starts when a nucleus is formed. The number of nuclei formed in differential time $d \tau$ is equal to

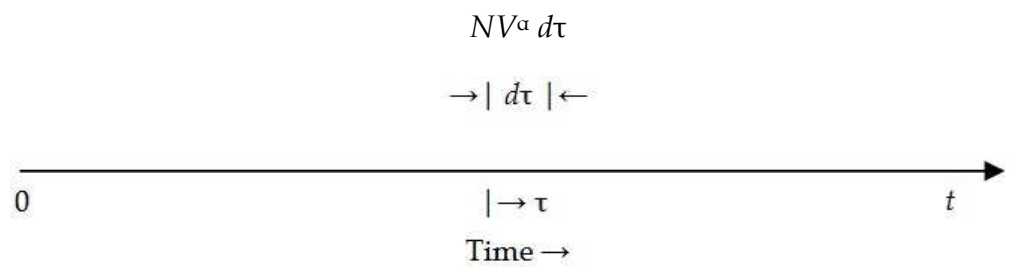

Fig. 11. Definition of $t$ and $\tau$ for derivation of solid state transformation equations (Ragone, 1994)

Assuming that the particles nucleated in this time $d \tau$ grow as spheres, the radius of the particles formed during $d \tau$, after they have grown to time $t$, is:

$$
\begin{gathered}
\int_{0}^{\mathrm{r}} \mathrm{dr}=\int_{\tau}^{\mathrm{t}} \mathrm{G} d \mathrm{t} \\
r=G(t-\tau)
\end{gathered}
$$

The volume of the particle nucleated during $d \tau$ at time $t$ is:

$$
\begin{gathered}
d V^{\beta}=\frac{4}{3} \Pi G^{3}(t-\tau)^{3}\left(N V^{\alpha}\right) d \tau \\
d V^{\beta}=\frac{4}{3} \Pi G^{3} N\left(V-V^{\beta}\right)(t-\tau)^{3} \mathrm{~d} \tau
\end{gathered}
$$

Early in the transformations, when $V^{\beta}$ is small, $V^{\beta}$ can be considered negligible with respect to $V$. In this case, the fraction transformed may be calculated as follows:

$$
\int_{0}^{V^{\beta}} d V^{\beta}=\int_{0}^{t} \frac{4}{3} \pi G^{3} N V(t-\tau)^{3} d \tau
$$




$$
\begin{gathered}
V^{\beta}=V \frac{\Pi}{3} G^{3} N t^{4} \\
x=\frac{V^{\beta}}{V}=\frac{\pi}{3} G^{3} N t^{4}
\end{gathered}
$$

To treat the regime beyond the early transformation the extended volume concept is adopted. In this case, the nucleation and growth rates are separated from geometrical considerations such as impingement. The extended volume $\left(V_{\mathrm{e}}\right)$ is the volume that would have been formed if the entire volume had participated in nucleation and growth, even that portion transformed $\left(V^{\beta}\right)$. In this case,

$$
\begin{gathered}
d V_{\mathrm{e}}^{\beta}=V \frac{4}{3} \Pi G^{3} N(t-\tau)^{3} d \tau \\
V_{\mathrm{e}}^{\beta}=\frac{4}{3} \Pi V \int_{0}^{t} G^{3} N(t-\tau)^{3} d \tau
\end{gathered}
$$

But the total volume is equal to the sum of the volumes of $\alpha$ and $\beta$ :

$$
\begin{gathered}
V=V^{\alpha}+V^{\beta} \\
\frac{V^{\alpha}}{V}=1-\frac{V^{\beta}}{V}=1-x
\end{gathered}
$$

where $x=V \beta / V$

The amount of $\beta$ formed, $d V \beta$, is the fraction of a times $d V_{\mathrm{e}}^{\beta}$

$$
d V^{\beta}=\left(1-\frac{V^{\beta}}{V}\right) d V_{e}^{\beta}
$$

Integrating Equation 46,

$$
V_{\mathrm{e}}^{\beta}=-V \ln \left(1-\frac{V^{\beta}}{V}\right)=-V \ln (1-x)
$$

Combining Equations 43 and 47 yields,

$$
-\ln (1-x)=\frac{4}{3} \Pi \int_{0}^{t} G^{3} N(t-\tau)^{3} d \tau
$$

If $G$ and $N$ are constant,

$$
\begin{aligned}
-\ln (1-x) & =\frac{4}{3} \Pi G^{3} N \int_{0}^{t}(t-\tau)^{3} d \tau=\frac{\pi}{3} G^{3} N t^{4} \\
x & =1-\exp \left(-\frac{\pi}{3} G^{3} N t^{4}\right)
\end{aligned}
$$

The resulting equation relating the fraction transformed to nucleation rate, growth rate and time is called Johnson-Mehl equation.

A similar treatment of the subject is given by Avrami. In general he expresses the fraction transformed as

$$
x=1-\exp \left(-k t^{\mathrm{n}}\right)
$$


where $n$ is called "the Avrami $n$ ". To determine the value of Avrami $n$ from Equation 50, the following mathematical manipulation is performed:

$$
\begin{gathered}
x=1-\exp \left(-k t^{\mathrm{n}}\right) \\
1-x=\exp \left(-k t^{\mathrm{n}}\right) \\
\ln (1-x)=-k t^{\mathrm{n}} \\
\ln [\ln (1-x)]=\ln k-n \ln t
\end{gathered}
$$

Thus the Avrami $n$ is the slope of the plot of the logarithm of the logarithm of $(1-x)$ versus the negative of the logarithm of $t$ (Ragone, 1994).

\subsection{Thermal analysis techniques}

The study of crystallization kinetics in glass-forming liquids has often been limited by the elaborate nature of the experimental procedures which are employed. The increasing use of thermoanalytical techniques such as differential thermal analysis (DTA) or differential scanning calorimetry (DSC) has, however, offered the promise of obtaining useful data with simple methods (Yinnon \& Uhlmann, 1983).

When a reaction occurs in thermal analysis, the change in heat content and in the thermal properties of the sample is indicated by a deflection (Kissinger, 1957). It is conventional to represent an endothermic effect by a negative deflection and an exothermic effect by a positive deflection (see Fig. 12). The deflections, whether positive or negative, are called peaks (Kissinger, 1956). If the reaction proceeds at a rate varying with temperature, possesses an activation energy the position of the peak varies with the heating rate if other experimental conditions are maintained fixed. This variation in peak temperature could be used to determine the energy of activation for first order reactions (Kissinger, 1957).

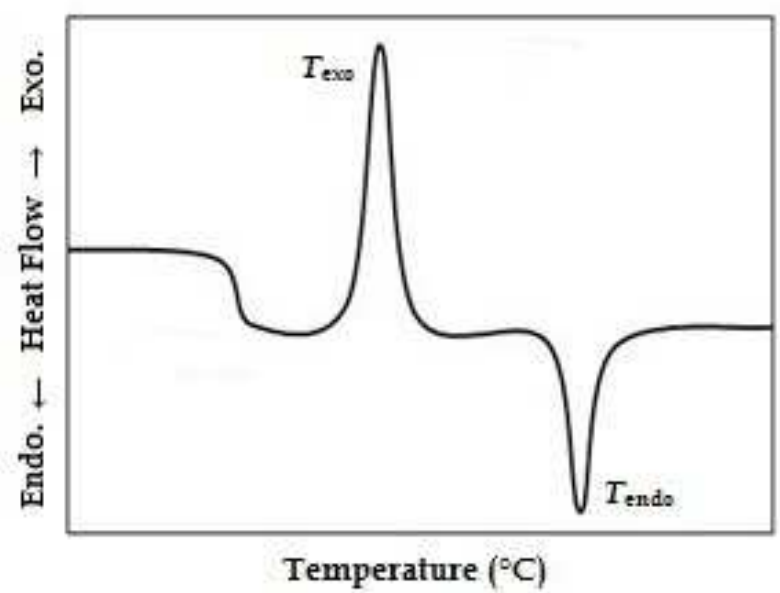

Fig. 12. A representative thermal analysis thermogram 
Differential thermal analysis (DTA) has been extensively used as a rapid and convenient means for detecting the reaction process. The rate of chemical reaction was analyzed quantitatively by DTA and the activation energies were obtained. Furthermore, this method was used to obtain the activation energy for the crystallization of glass, assuming that the process of crystallization is a first order reaction (Matusita \& Sakka, 1981). DSC measurements are useful in obtaining kinetic parameters related to the glass crystallization process especially in non-isothermal method due to the rapidity of this thermoanalytical technique (Araújo \& Idalgo, 2009; Cheng et al., 2007).

\subsection{Thermal analysis methods}

\subsubsection{Isothermal method}

In the isothermal method, kinetic parameters of amorphous materials crystallization are obtained by monitoring the shift in the crystallization peak as a function of time (Prasad \& Varma, 2005). Crystallization peak temperatures, $T_{p}$ and crystallized volume fractions, $x$, are determined from the thermal analysis curves with respect to time in isothermal method.

In isothermal analysis, the volume fraction crystallized, $x$, at any time $t$ is given as $x=S_{t} / S$ where $S$ is the total area of the exothermic peak between the time $t_{i}$ at which the crystallization begins and the time $t_{f}$ at which the crystallization is completed. $S_{t}$ is the area between $t_{i}$ and $t$ (see Fig. 13) (Ray et al., 1991).

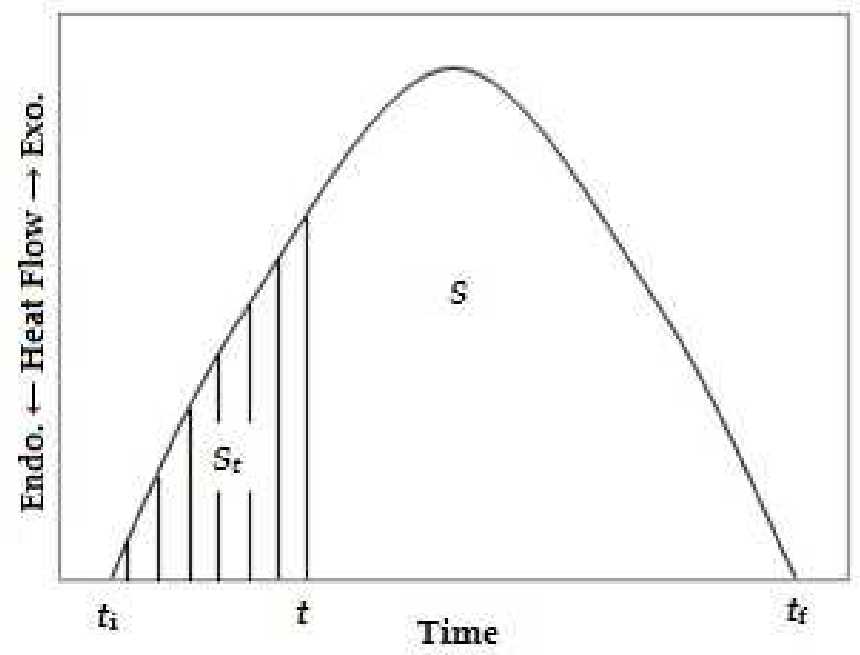

Fig. 13. Computation of the volume fraction crystallized, $x$, in isothermal method (Prasad \& Varma, 2005)

Isothermal investigation of crystallization in amorphous materials can be described by the Johnson-Mehl-Avrami equation as given in Equation 55 (Araújo \& Idalgo, 2009; Avrami, 1939, 1940; Çelikbilek et al., 2011; Prasad \& Varma, 2005).

From the slopes of the linear fits to the experimental data from a plot of $\ln [-\ln (1-x)]$ versus $\ln t, k$ and $n$ values are calculated for different isothermal hold temperatures (see Fig. 14). 


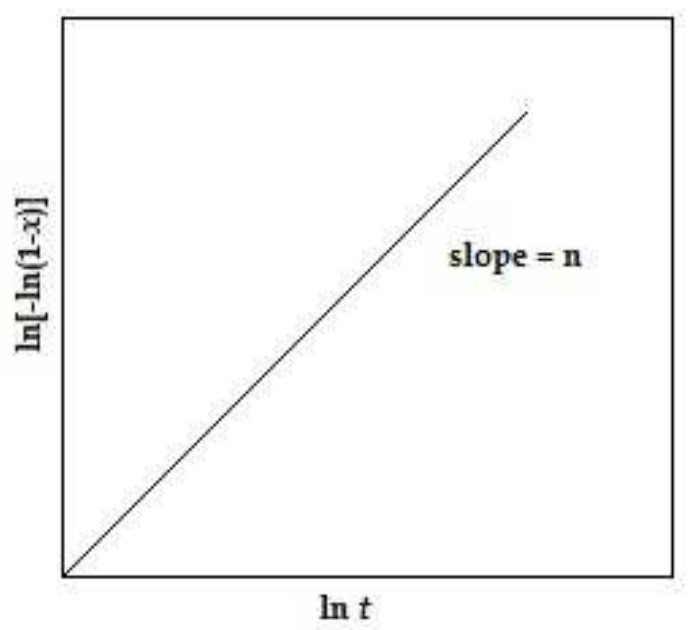

Fig. 14. Plot of $\ln [-\ln (1-x)]$ against $\operatorname{lnt}$ for determining the Avrami parameter, $n$

The activation energy can be evaluated by the Arrhenius-type equation (Araújo \& Idalgo, 2009; Çelikbilek et al., 2011; Prasad \& Varma, 2005):

$$
\ln (k)=\ln k_{0}-E_{\mathrm{A}} / \mathrm{RT}
$$

where $k$ is the reaction rate constant, $k_{0}$ is the frequency factor, $E_{A}$ is the activation energy, $R$ is the gas constant. The activation energy for several isothermal temperatures is calculated from the slopes of the linear fits to the experimental data from a plot of $\ln k$ versus $1 / T$ (see Fig. 15).

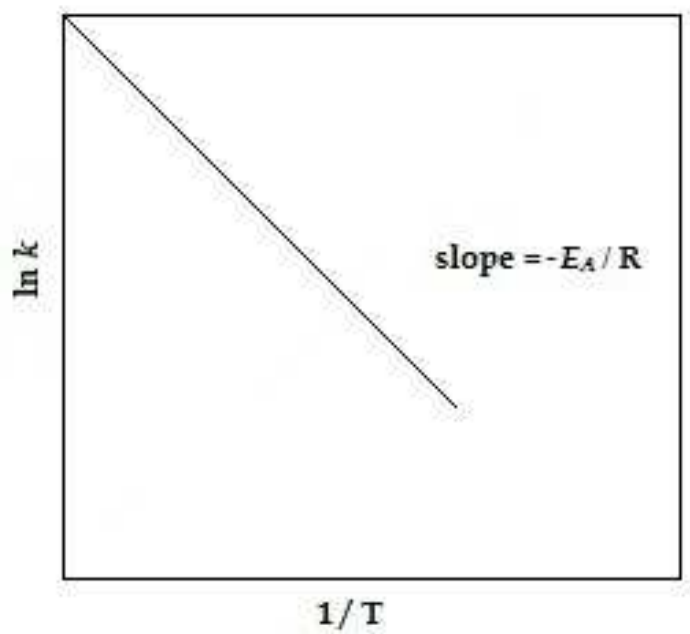

Fig. 15. Plot of lnk against $1 / \mathrm{T}$ for determining the activation energy, $E_{A}$ 
In crystallization kinetic studies, as-cast (non-nucleated) and pre-nucleated samples can be used to recognize the effect of increasing and constant number of nuclei on the crystallization mechanism, respectively (Çelikbilek et al., 2011; Prasad \& Varma, 2005). For the as-cast (non-nucleated) samples, when the nucleation takes place during thermal analysis, the number of nuclei of the as-cast sample is proportional to the heating rate. For the pre-nucleated samples, the number of nuclei of the pre-nucleated sample does not depend on the heating rate (Çelikbilek et al., 2011).

Crystallization mechanism of amorphous materials can be detected regarding to the following approaches; when the nucleation rate is zero during the thermal analysis experiment, $n=m$, when nucleation takes place during thermal analysis, $n=m+1$ and when surface crystallization is the predominant mechanism, $n=m=1$, where the parameters of $n$ and $m$ represent the values of the growth morphology depending on the crystallization mechanism (Çelikbilek et al., 2011; Matusita \& Sakka, 1981; Prasad \& Varma, 2005). As seen in Table 1, different crystallization mechanisms appear for different numerical factors, such as rod-like for one dimensional growth or surface crystallization $(m$ $=1)$, disk-like for two-dimensional growth $(m=2)$ and spherical for three-dimensional growth $(m=3)$ (Çelikbilek et al., 2011; Matusita \& Sakka, 1981; Matusita et al., 1984; Prasad \& Varma, 2005; Ray et al. 1991).

\begin{tabular}{lcc}
\hline Crystallization mechanism & $n$ & $m$ \\
\hline Bulk crystallization with a constant number of nuclei & & \\
Three-dimensional growth of crystals & 3 & 3 \\
Two-dimensional growth of crystals & 2 & 2 \\
One-dimensional growth of crystals & 1 & 1 \\
Bulk crystallization with an increasing number of nuclei & & \\
Three-dimensional growth of crystals & 4 & 3 \\
Two-dimensional growth of crystals & 3 & 2 \\
One-dimensional growth of crystals & 2 & 1 \\
Surface crystallization & 1 & 1 \\
\hline
\end{tabular}

Table 1. Values of $n$ and $m$ for different crystallization mechanisms (Matusita \& Sakka, 1981)

\subsubsection{Non-isothermal method}

Non-isothermal measurements offer some advantages if compared with isothermal studies. The kinetics of crystallization of several amorphous materials has been extensively obtained from thermal analysis techniques in isothermal mode. However, non-isothermal measurements, using a constant heating rate until the complete crystallization, are usually applied to study the devitrification on different glasses since the rapidity with which this thermoanalytical technique can be performed (Araújo \& Idalgo, 2009). In the non-isothermal method, crystallization peak temperatures, $T_{p}$ and crystallized volume fractions, $x$, are determined from the thermal analysis curves with respect to temperature. The volume fraction crystallized, $x$, at any temperature $T$ is given as $x=S_{T} / S$, where $S$ is the total area of the exothermic peak between the temperature, $T_{i}$, at which the crystallization begins and the temperature, $T_{f}$, at which the crystallization is completed and $S_{T}$ is the partial area of the exothermic peak up to the temperature $T$ (see Fig. 16) (Ray et al., 1991). 


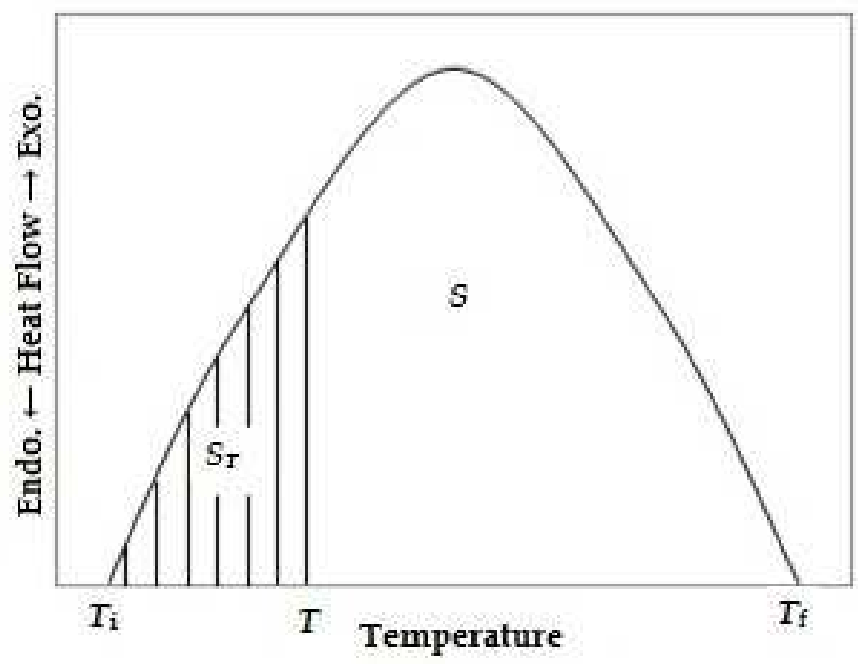

Fig. 16. Computation of the volume fraction crystallized, $x$, in non-isothermal method (Çelikbilek et al., 2011; Prasad \& Varma, 2005)

Some authors have applied the Johnson-Mehl-Avrami equation to the non-isothermal crystallization process, although it is not appropriate because the Johnson-Mehl-Avrami equation was derived for isothermal crystallization. Table 2 shows different approaches for the interpretation of the kinetic data obtained from thermal analysis measurements. The Kissinger equation was basically developed for studying the variation of the peak crystallization temperature with heating rate. According to Kissinger's method, the transformation under non-isothermal condition is represented by a first-order reaction. Moreover, the concept of nucleation and growth has not been included in Kissinger equation. Matusita et al. have developed a method on the basis of the fact that crystallization

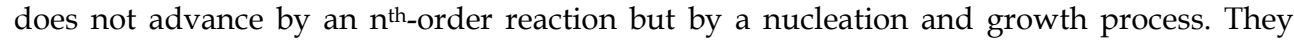
emphasized that crystallization mechanisms such as bulk crystallization or surface crystallization should be taken into account for obtaining avtivation energy. In addition to activation energy, Matusita's method provides information about the Avrami exponent and

\begin{tabular}{ccc}
\hline Method & Approach & \\
\hline Ozawa & $\ln [-\ln (1-x)]=-n \ln \beta+$ const & (Equation 57) \\
\hline $\begin{array}{c}\text { Kissinger modified by } \\
\text { Matusita et al. }\end{array}$ & $\ln \left(\frac{T_{\mathrm{p}}^{2}}{\beta^{\mathrm{n}}}\right)=\frac{m E_{\mathrm{A}}}{\mathrm{R} T_{\mathrm{P}}}+$ const & (Equation 58) \\
\hline $\begin{array}{c}\text { Ozawa modified by Matusita } \\
\text { et al. }\end{array}$ & $\ln \beta=-1.052\left(\frac{m E_{\mathrm{A}}}{n R T_{\mathrm{p}}}\right)-\left\{\frac{\ln [-\ln (1-x)]}{n}\right\}+$ const & (Equation 59) \\
\hline Augis and Bennett & $\ln \left(\beta / T_{\mathrm{p}}\right)=-E_{\mathrm{A}} / R T_{\mathrm{p}}+\ln k_{o}$ & (Equation 60) \\
\hline Afify & $\begin{array}{c}\ln \left(\beta / T_{\mathrm{p}}^{2}\right)=-(m / n)\left(E_{\mathrm{A}} / R T_{\mathrm{p}}\right)+\text { constant } \\
\ln (\beta)=-(m / n)\left(E_{\mathrm{A}} / R T_{\mathrm{p}}\right)+\text { constant }\end{array}$ & $\begin{array}{c}\text { (Equation 61) } \\
\text { (Equation 62) }\end{array}$ \\
\hline
\end{tabular}

Table 2. Different methods for interpretation of non-isothermal kinetic data 
dimensionality of growth. Augis and Bennett method is helpful in obtaining kinetic parameters such as frequency factor $\left(k_{\mathrm{o}}\right)$, rate constant $(k)$ along with activation energy of crystallization and therefore preferred for the calculation of the kinetics over the other models (Deepika et al., 2009).

Ozawa and Kissinger plots are the most commonly used equations to calculate nonisothermal kinetic data, such as Avrami constant, $n$ and crystallization activation energy, $E_{A}$, respectively (Çelikbilek et al., 2011; Kissinger, 1956; Ozawa, 1971; Prasad \& Varma, 2005).

In the non-isothermal method, the values of the Avrami parameter, $n$, are determined from the Ozawa equation (Çelikbilek et al., 2011; Ozawa, 1971; Prasad \& Varma, 2005):

$$
\ln [-\ln (1-x)]=-n \ln \beta+\text { const }
$$

where $x$ is the crystallized volume fraction at $T$ for the heating rate of $\beta$. From the slopes of the linear fits to the experimental data from a plot of $\ln [-\ln (1-x)]$ versus $\ln \beta, n$ values are calculated (see Fig. 17). Crystallization mechanism, $m$, of the glass samples can be detected from Matusita et al.'s approach (Matusita \& Sakka, 1981) as shown in Table 1.

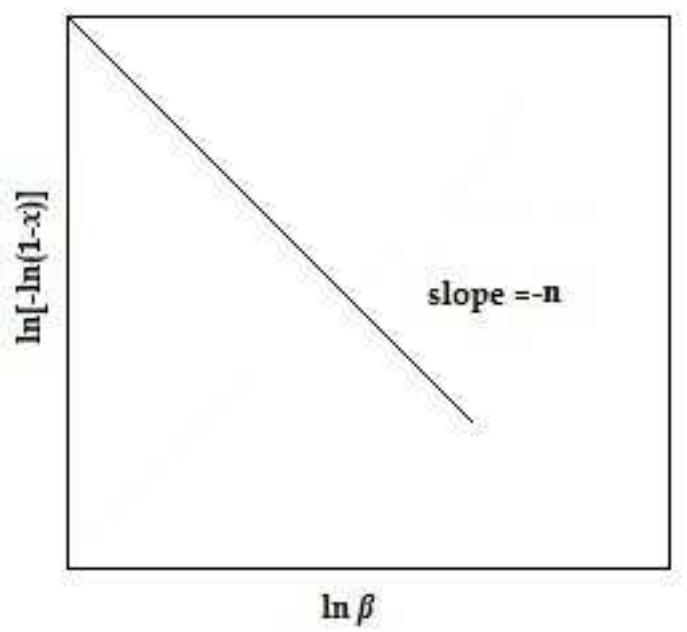

Fig. 17. Plot of $\ln [-\ln (1-x)]$ against $\ln \beta$ for determining the Avrami parameter, $n$

The activation energy can be evaluated by the modified Kissinger equation by Matusita et al. (Araújo \& Idalgo, 2009; Çelikbilek et al., 2011; Kissinger, 1956; Matusita \& Sakka, 1981; Prasad \& Varma, 2005):

$$
\ln \left(\frac{T_{\mathrm{p}}^{2}}{\beta^{n}}\right)=\frac{\mathrm{m} E_{\mathrm{A}}}{R T_{\mathrm{P}}}+\text { const }
$$

where $T_{p}$ is the crystallization peak temperature for a given heating rate $\beta, E_{A}$ is the activation energy, $R$ is the gas constant, $n$ is the Avrami parameter and $m$ is the numerical factor of crystallization mechanism. The activation energy is calculated from the slopes of the linear fits to the experimental data from a plot of $\ln \left(T_{p}{ }^{2} / \beta^{n}\right)$ versus $1 / T_{p}$ (see Fig. 18). 


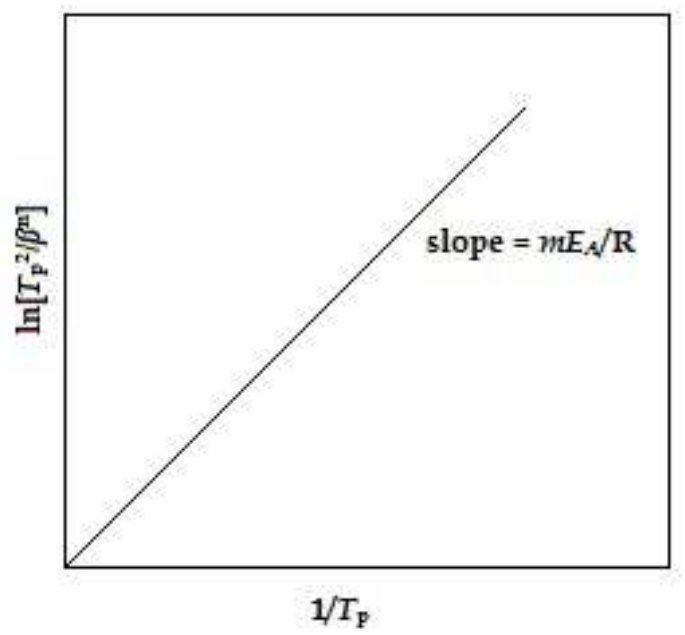

Fig. 18. Plot of $\ln \left[T_{\mathrm{p}}^{2} / \beta^{\mathrm{n}}\right]$ against $1 / T_{\mathrm{p}}$ for determining the activation energy, $E_{A}$

There exist also different approaches for the interpretation of the activation energy in the literature, such as the modified Ozawa equation by Matusita et al. (Equation 59) (Matusita \& Sakka, 1981):

$$
\ln \beta=-1.052\left(\frac{\mathrm{m} E_{\mathrm{A}}}{n R T_{\mathrm{p}}}\right)-\left\{\frac{\ln [-\ln (1-x)]}{n}\right\}+\text { const }
$$

where $x$ is the crystallized volume fraction, $\beta$ is the heating rate, $T_{\mathrm{p}}$ is the peak temperature, $E_{A}$ is the activation energy, $R$ is the gas constant, $n$ is the Avrami parameter and $m$ is the crystallization mechanism.

The activation energy of crystallization can also be determined by an approximation proposed by Augis and Bennett (Augis \& Bennett, 1978). The relation used by them is of the form:

$$
\ln \left(\beta / T_{p}\right)=-E_{A} / R T_{p}+\ln k_{o}
$$

where, $k_{\mathrm{o}}$ is the frequency factor and $R$ is gas constant. The plot of $\ln \left(\beta / T_{\mathrm{p}}\right)$ against $1 / T_{\mathrm{p}}$ gives activation energy of crystallization $\left(E_{\mathrm{A}}\right)$.

This method has an extra advantage over the modifed Ozawa method employed in the literature for the determination of activation energy of crystallization that the intercept of $\ln \left(\beta / T_{\mathrm{p}}\right)$ against $1000 / T_{\mathrm{p}}$ gives the value of pre-exponential

factor $k_{\mathrm{o}}$ of Arrhenius equation (Eq. 56), which is defined as the number of attempts made by the nuclei per second to overcome the energy barrier. This also provides information for the calculation of number of nucleation sites, present in the material for crystal growth (Deepika et al., 2009). 
The value of activation energy can also be calculated also by using the variation of $T_{\mathrm{p}}$ with the heating rate $\beta$ for both crystallization phases (Afify, 1990; Afify et al., 1991). By using similar relations to Kissinger equation, the relations can be written in the form:

$$
\begin{gathered}
\ln \left(\beta / T_{\mathrm{p}}^{2}\right)=-(m / n)\left(E_{\mathrm{A}} / R T_{\mathrm{p}}\right)+\text { const } \\
\ln (\beta)=-(m / n)\left(E_{\mathrm{A}} / R T_{\mathrm{p}}\right)+\text { const }
\end{gathered}
$$

where, $R$ is gas constant, $T_{\mathrm{p}}$ is the peak temperature, $n$ is the Avrami parameter and $m$ is the crystallization mechanism.

\subsection{Crystallization kinetic studies in amorphous materials}

Numerous studies exist on crytallization kinetics of amorphous materials, such as glasses (Araújo, \& Idalgo, 2009; Araújo, 2009; Cheng, 2007; Çelikbilek, 2010; Çelikbilek, 2011; ElMallawany, 1997; Idalgo, 2006; Jeong, 2007; Prasad \& Varma 2005; Ray, C.S., Huang, W.H. \& Day, 1991; Shaaban, 2009; Yukimitu, 2005), amorphous alloys (Abu El-Oyoun, 2009; Afify, 1990; Afify, 1991; Al-Ghamdi, 2010; Al-Ghamdi, 2011; Aly, 2009; Dahshan, 2010; Deepika, 2009; Elabbar, 2008; Huang, 2008; Mehta, 2004; Yahia, 2011, Zhang, 2008), amorphous thin films (Abdel-Wahaba, 2005; Bhargava, 2010; Chen \& Wu, 1999; Hajiyev, 2009; Lei, 2010; Liu \& Duh, 2007; Seeger \& Ryder, 1994), amorphous nanomaterials (Ahmadi, 2011; Gridnev, 2008; Qin, 2004; Tomasz, 2010), etc. In this section, selected studies reported in the literature on crystallization kinetics of different types of amorphous materials were given to make the theory of kinetics more understandable for the reader.

\subsubsection{Glasses}

Isothermal crystallization kinetic studies in the glass system $(100-x) \mathrm{LiBO}_{2}-x \mathrm{Nb}_{2} \mathrm{O}_{5}(5 \leq x \leq 20$, in molar ratio) have been realized using differential thermal analyses by Prasad et al. (Prasad \& Varma, 2005). The isothermal experiments were carried out by heating the samples to the desired temperature at a rate of $50{ }^{\circ} \mathrm{C} / \mathrm{min}$. After attaining the required temperature, the run was held for a period of about 30 seconds to reach the equilibrium. The temperature range of $527-547^{\circ} \mathrm{C}$ with an interval of $5{ }^{\circ} \mathrm{C}$ was selected for isothermal experiments because the glass shows reasonable peak shapes in this range, which is recommended for accurate data analyses.

The crystallized fraction $x$ as a function of time at all the holding temperatures is shown in Fig. 19. It reveals that the time taken to complete the crystallization peak is indirectly proportional to the isothermal holding temperature. A typical isothermal DTA trace obtained at $537^{\circ} \mathrm{C}$ (holding temperature) is shown in the inset of Fig. 19.

Plots of $\ln [-\ln (1-x)]$ against $\ln t$ are shown in Fig. 20. Values of Avrami exponent $n$ and the reaction rate constants $k$ were determined by least square fits of the experimental data. The average value of $n$ is 2.62. Since $n$ takes only integer values from 1 to 4 , the $n$ (close to 3 ) value observed in the present study indicates the near three-dimensional growth of $\mathrm{LiNbO}_{3}$ (see Table 1). The values of $\ln k$ are determined for all the temperatures from the plots of $\ln [-$ $\ln (1-x)$ ] against $\ln t$ (Fig. 20). 


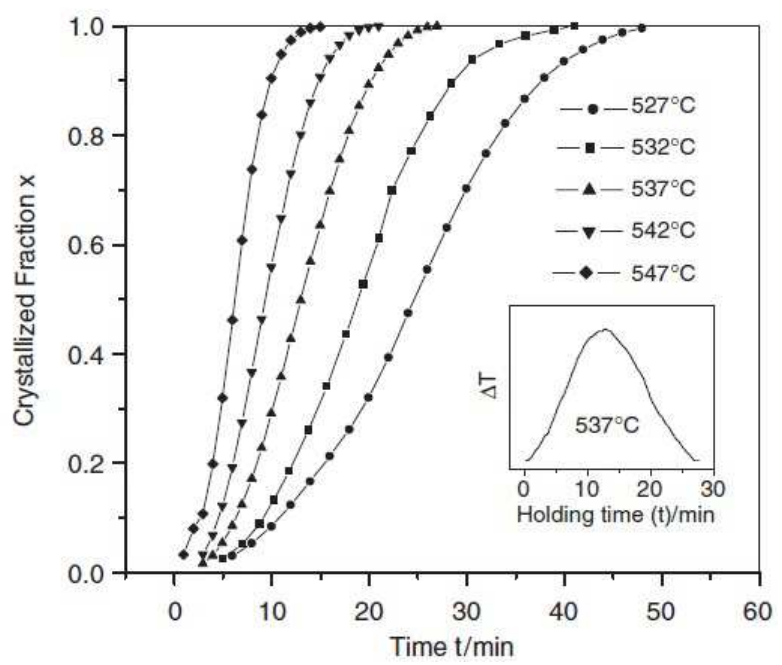

Fig. 19. The crystallized fraction $x$ as a function of isothermal time. Inset shows the isothermal differential thermal analyses trace obtained at $537^{\circ} \mathrm{C}$ (Prasad \& Varma, 2005)

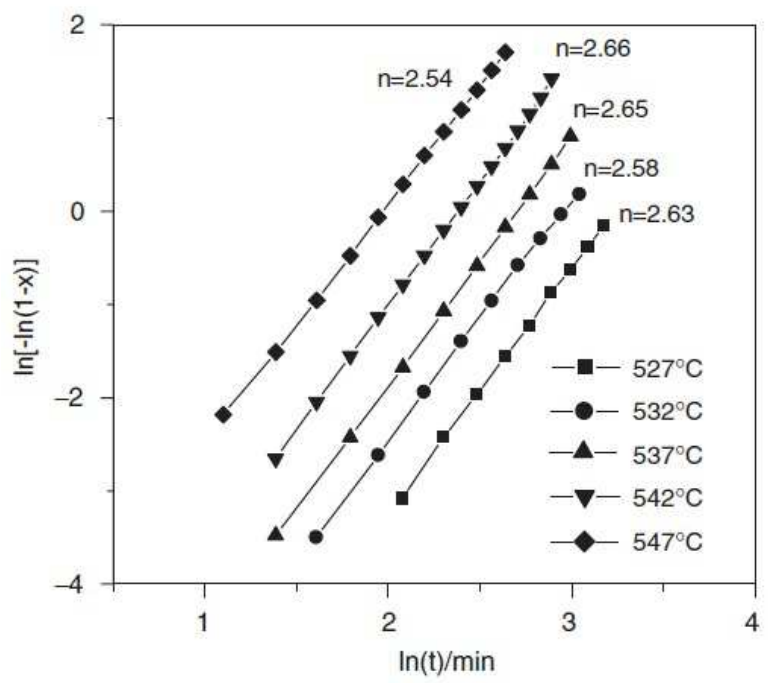

Fig. 20. Plot of $\ln [-\ln (1-x)]$ against $\ln t$ for determining the $n$ (Prasad \& Varma, 2005)

A plot of $\ln k$ versus $1 / T$ shown in Fig. 21 yielded the activation energy, $E_{\mathrm{A}}$, to be 293 $\mathrm{kJ} / \mathrm{mol}$ (Prasad \& Varma, 2005).

Non-isothermal crystallization kinetics of the $(1-x) \mathrm{TeO}_{2}-x \mathrm{WO}_{3}$ (where $x=0.10,0.15$ and 0.20 , in molar ratio) glass system was studied by Çelikbilek et al. and DSC curves of the as-cast (non-nucleated) sample recorded at different heating rates, $\beta$, are shown in Fig. 22 . The $T$ value for the calculation of the volume fraction crystallized of $0.90 \mathrm{TeO}_{2}-0.10 \mathrm{WO}_{3}$ glass was determined at $420^{\circ} \mathrm{C}$ (Çelikbilek et al., 2011). 


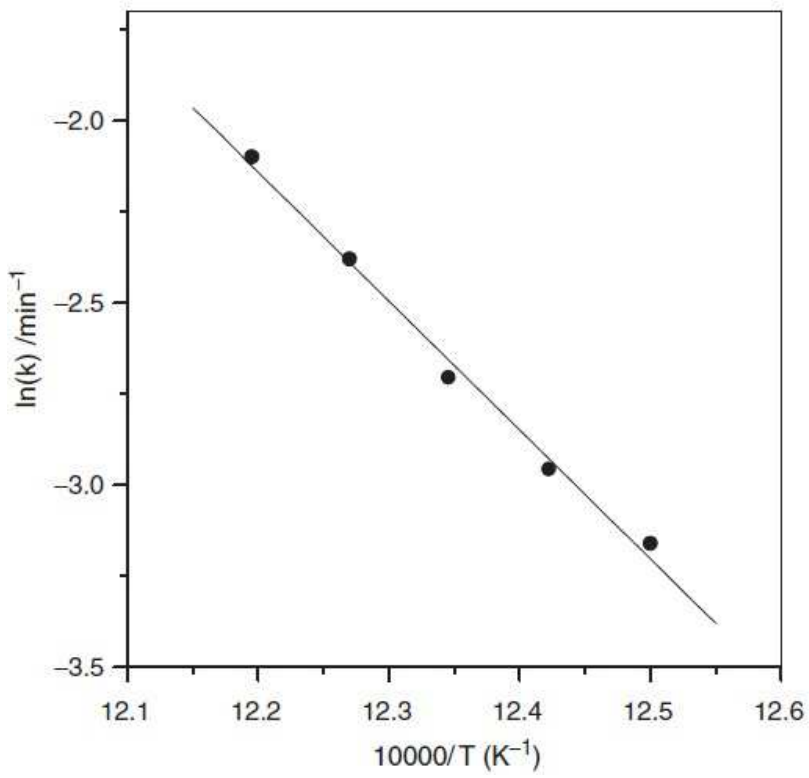

Fig. 21. Plot of $\ln k$ versus $1 / T$ from which the values of crystallization activation energy are obtained (Prasad \& Varma, 2005)

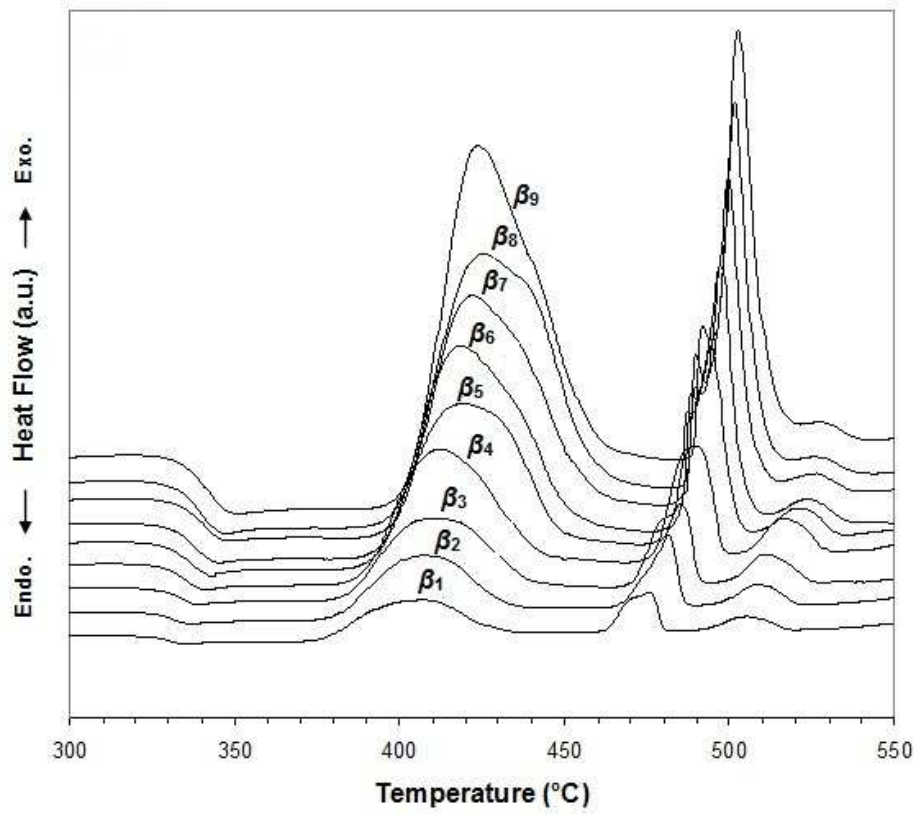

Fig. 22. DSC curves with heating rate $\beta\left(5,7.5,10,15,20,25,30,35\right.$ and $\left.40{ }^{\circ} \mathrm{C} / \mathrm{min}\right)$ for $0.90 \mathrm{TeO}_{2}-0.10 \mathrm{WO}_{3}$ sample (Çelikbilek et al., 2011) 
The values of the Avrami parameter, $n$, were calculated from the linear fits to the experimental data based on the Ozawa equation (Equation 57), as shown in Fig. 23. The $n$ value was determined as 1.14 for $0.90 \mathrm{TeO}_{2}-0.10 \mathrm{WO}_{3}$ glasses. On the basis of the determination about the non-integer value of the Avrami parameter, in this study the $n$ value was determined as 1, indicating the formation of surface crystallization during the crystallization process (see Table 1).

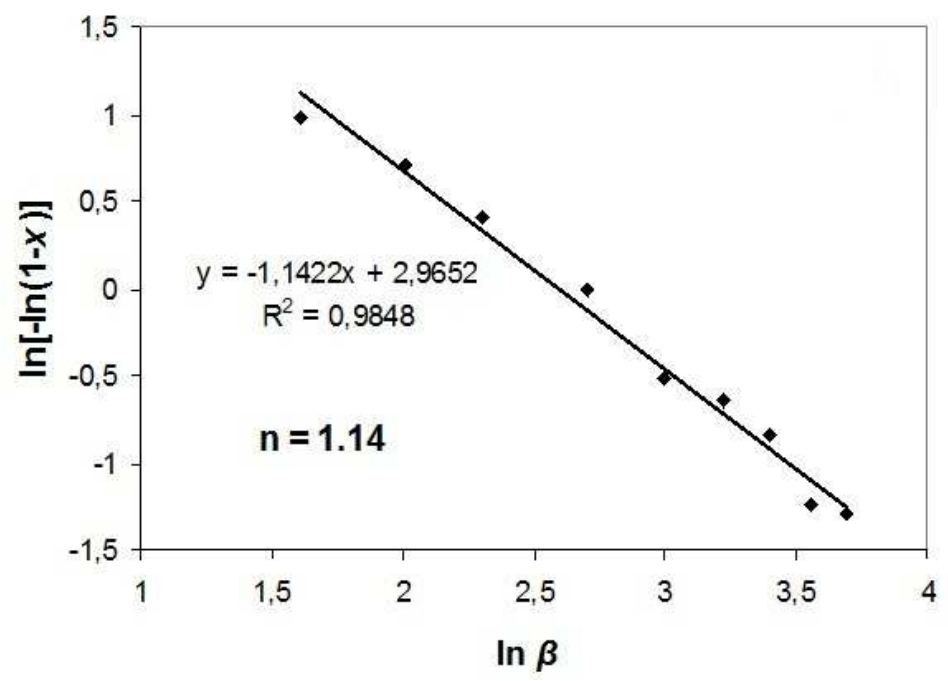

Fig. 23. The Ozawa plot for determining $n$ associated with the first exotherm of the $0.90 \mathrm{TeO}_{2}-0.10 \mathrm{WO}_{3}$ sample (Çelikbilek et al., 2011)

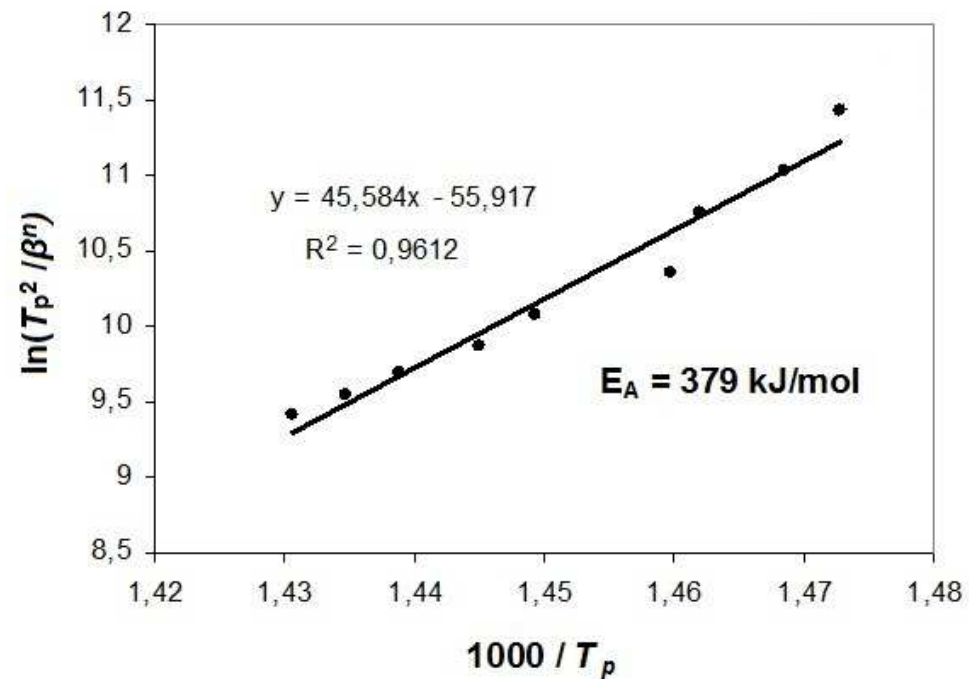

Fig. 24. The Kissinger plots for determining $E_{\mathrm{A}}$ associated with the first exotherm of the prenucleated $0.90 \mathrm{TeO}_{2}-0.10 \mathrm{WO}_{3}$ sample (Çelikbilek et al., 2011) 
Using the modified Kissinger equation (Equation 58), activation energy, $E_{A}$, for the first crystallization reaction of $0.90 \mathrm{TeO}_{2}-0.10 \mathrm{WO}_{3}$ glass was determined from the linear fits of $\ln \left(T_{p}^{2} / \beta^{n}\right)$ versus $1 / T_{p}$ plots, as shown in Fig. 24 . The activation energy of the first exotherm was calculated as $379 \mathrm{~kJ} / \mathrm{mol}$. Comparing with this result, in another study realized by Çelikbilek et al., the $E_{\mathrm{A}}$ value was determined as $372 \mathrm{~kJ} / \mathrm{mol}$ by applying the modified Ozawa method from the slopes of the linear fits to the experimental data from a plot of $\ln \beta$ versus $1 / T_{\mathrm{p}}$ for $0.90 \mathrm{TeO}_{2}-0.10 \mathrm{WO}_{3}$ sample.

To determine the crystallization mechanism of the glasses with fixed nuclei number, $0.90 \mathrm{TeO}_{2}-0.10 \mathrm{WO}_{3}$ sample was pre-nucleated by heat-treating for 2 hours at $350{ }^{\circ} \mathrm{C}$. The prenucleation temperature was determined by nucleating the as-cast glass sample for 2 hours at three different temperatures between $T_{g}$ and $T_{p}$. The nucleation temperature which corresponds to the maximum peak temperature was selected as the pre-nucleation temperature $\left(350^{\circ} \mathrm{C}\right)$ (Çelikbilek et al., 2011).

The value of the Avrami constant of $0.90 \mathrm{TeO}_{2}-0.10 \mathrm{WO}_{3}$ glass pre-nucleated at $350{ }^{\circ} \mathrm{C}$ is shown in Fig. 25. The $n$ value of the pre-nucleated sample was calculated as 1 from the Ozawa equation (Equation 57) and while the number of nuclei do not depend on the heating rate for pre-nucleated samples, according to the approach $n=m$, the mechanism was determined as one-dimensional growth of the crystals (see Table 1). The $n$ value calculated for the as-cast $0.90 \mathrm{TeO}_{2}-0.10 \mathrm{WO}_{3}$ glass was also calculated as 1 , indicating the surface crystallization.

The activation energy, $E_{A}$, of the first crystallization reaction of pre-nucleated $0.90 \mathrm{TeO}_{2}-$ $0.10 \mathrm{WO}_{3}$ glass was calculated using the Kissinger equation, as shown in Fig. 26. The $E_{A}$ value of the pre-nucleated sample was determined as $382 \mathrm{~kJ} / \mathrm{mol}$, very close to the calculated $E_{A}$ value of the as-cast sample $(379 \mathrm{~kJ} / \mathrm{mol})$ and from the obtained data it was concluded that constant or increasing number of nuclei does not have a significant effect on crystallization activation energy.

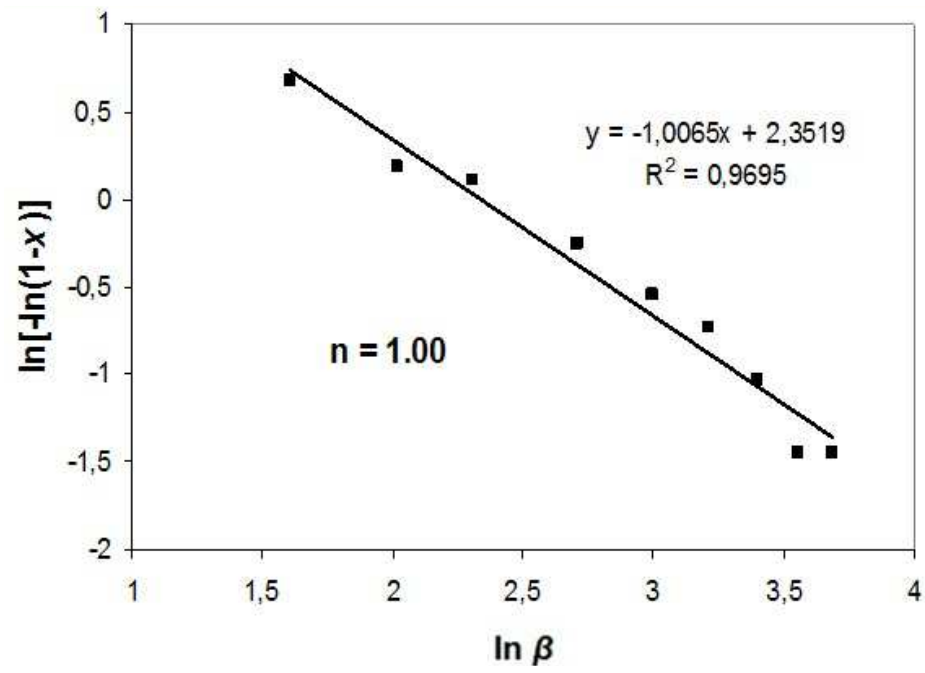

Fig. 25. The Ozawa plot for determining $n$ associated with the first exotherm of the $0.90 \mathrm{TeO}_{2}-0.10 \mathrm{WO}_{3}$ sample pre-nucleated at $350{ }^{\circ} \mathrm{C}$ for 2 hours (Çelikbilek et al., 2011) 


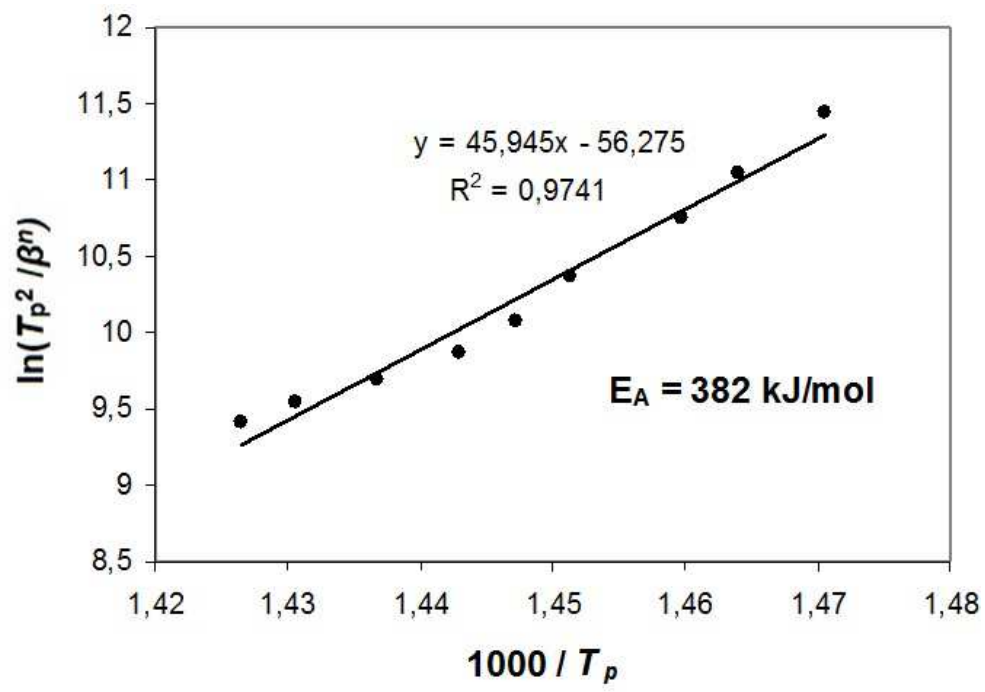

Fig. 26. The Kissinger plot for determining $E_{\mathrm{A}}$ associated with the first exotherm of the $0.90 \mathrm{TeO}_{2}-0.10 \mathrm{WO}_{3}$ sample pre-nucleated at $350{ }^{\circ} \mathrm{C}$ for 2 hours (Çelikbilek et al., 2011)
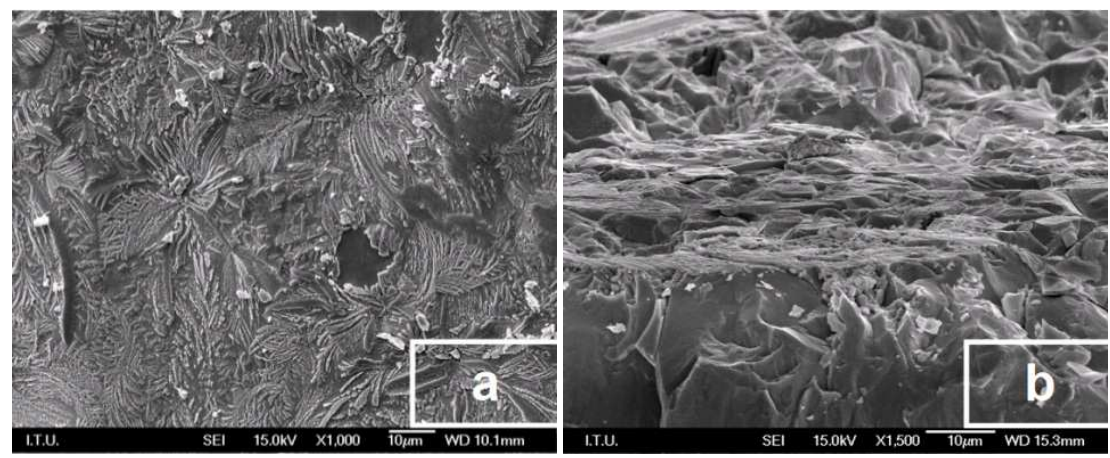

Fig. 27. SEM micrographs of the $0.90 \mathrm{TeO}_{2}-0.10 \mathrm{WO}_{3}$ sample heat-treated at $410{ }^{\circ} \mathrm{C}$ (a) surface, (b) cross-section (Çelikbilek et al., 2011)

Fig. 27a-b represents the SEM micrographs taken from the surface and the cross-section of the $0.90 \mathrm{TeO}_{2}-0.10 \mathrm{WO}_{3}$ sample heat-treated at $410{ }^{\circ} \mathrm{C}$, above the first crystallization onset temperature, respectively. Fig. 27a exhibits the presence of dendritic leaf-like crystallites differently oriented on the surface. However, in the cross-sectional micrograph (see Fig. 27b), a typical amorphous structure without any crystallization on bulk structure can be clearly observed following the crystallites on the surface. Based on the SEM investigations, it was determined that the crystallites formed on the surface and did not diffuse into the bulk structure proving the surface crystallization mechanism (Çelikbilek et al., 2011). 


\subsubsection{Amorphous alloys}

Non-isothermal crystallization kinetic investigation of $\mathrm{Se}_{58} \mathrm{Ge}_{42-x} \mathrm{~Pb}_{x}(x=9,12)$ alloy studied by Deepika et al. is given here as an example of the crystallization kinetics in amorphous alloys. In their study, glassy alloys of $\mathrm{Se}_{58} \mathrm{Ge}_{33} \mathrm{~Pb}_{9}$ and $\mathrm{Se}_{58} \mathrm{Ge}_{30} \mathrm{~Pb}_{12}$ were prepared by meltquenching technique and after realizing thermal analyses, the samples were annealed at 633 and $643 \mathrm{~K}$, which lie between the first and second crystallization, respectively. The activation energy of crystallization for the first and second crystallization stages of $\mathrm{Se}_{58} \mathrm{Ge}_{33} \mathrm{~Pb}_{9}$ and $\mathrm{Se}_{58} \mathrm{Ge}_{30} \mathrm{~Pb}_{12}$ glassy systems was derived using the approximation methods developed by the Kissinger (Equation 58), Matusita (Equation 59), Augis and Bennett (Equation 60). The values of activation energy of crystallization of as-prepared and annealed samples using different theoretical models are given in Table 3 (Deepika et al., 2009).

\begin{tabular}{lcccccc}
\hline & \multicolumn{4}{c}{ Activation energy of crystallization (kJ/mol) } \\
\cline { 2 - 7 } Models applied & \multicolumn{3}{c}{$\mathrm{Se}_{58} \mathrm{Ge}_{33} \mathrm{~Pb}_{9}$} & \multicolumn{3}{c}{$\mathrm{Se}_{58} \mathrm{Ge}_{30} \mathrm{~Pb}_{12}$} \\
\cline { 2 - 7 } & \multicolumn{2}{c}{ Before annealing } & After annealing & \multicolumn{2}{c}{ Before annealing } & After annealing \\
& $167.06 \pm 0.88$ & $165.29 \pm 0.45$ & $144.97 \pm 0.88$ & $171.46 \pm 1.19$ & $146.15 \pm 2.03$ & $139.71 \pm 1.13$ \\
\hline Kissinger Model & II peak & & & & & \\
Augis-Bennett & $155.65 \pm 1.37$ & $168.20 \pm 2.27$ & $66.35 \pm 0.77$ & $195.66 \pm 0.53$ & $186.43 \pm 3.12$ & $134.22 \pm 2.94$ \\
Method & $330.34 \pm 7.46$ & $316.28 \pm 2.0$ & $237.58 \pm 1.33$ & $384.52 \pm 3.79$ & $412.39 \pm 2.61$ & $195.60 \pm 1.96$ \\
Matusita Model & & &
\end{tabular}

Table 3. Activation energy of crystallization of as-prepared and annealed samples of $\mathrm{Se}_{58} \mathrm{Ge}_{33} \mathrm{~Pb}_{9}$ and $\mathrm{Se}_{58} \mathrm{Ge}_{30} \mathrm{~Pb}_{12}$ glassy systems using different theoritical models

(Deepika et al., 2009)

From Table 3, it is observed that activation energy of crystallization decreases after annealing. This means that group of atoms in the glassy state requires less amount of energy to jump to crystalline state hence, making the sample less stable and more prone to crystallization. This is again an indication of the fact that annealing of glass leads it to a quicker crystallization. The crystallization mechanism of crystals decreases to one dimension from two and three dimensions after annealing, suggesting a decrease from bulk nucleation to surface nucleation in annealed samples.

It is also observed that activation energies of amorphous alloys calculated by means of the different theoretical models differ substantially from each other. This difference in the activation energy as calculated with the different models may be attributed to the different approximations used in the models.

\subsubsection{Amorphous thin films}

The crystallization kinetics in $\mathrm{Ni}_{50.54} \mathrm{Ti}_{49.46}$ film was studied by Liu et al. using differeantial scanning calorimetry through non-isothermal and isothermal techniques. $\mathrm{Ni}_{50.54} \mathrm{Ti}_{49.46}$ thin films were prepared by a mixed NiTi target using DC magnetron sputtering. The NiTi thin film was deposited on Si wafer and the substrate was unheated to achieve the amorphous structure. For non-isothermal analyses, a set of DSC scans was recorded at heating rates ranging from 5 to $50{ }^{\circ} \mathrm{C} / \mathrm{min}$. For isothermal analyses, the amorphous samples were first heated to a fixed temperature with $250^{\circ} \mathrm{C} / \mathrm{min}$ (between 793 and $823 \mathrm{~K}$ ), and then held for a certain period of time until fully crystalline state was achieved. 
The activation energy for crystallization was determined to be 411 and $315 \mathrm{~kJ} / \mathrm{mol}$ by Kissinger (Equation 58) and Augis \& Bennett (Equation 60) method, respectively (Fig. 28a-b) (Liu \& Duh, 2007). Comparing with this study, previous works on near equiatomic NiTi films showed that the activation energy was 370-419 kJ/mol (Chen \& Wu 1999; Seeger \& Ryder, 1994).
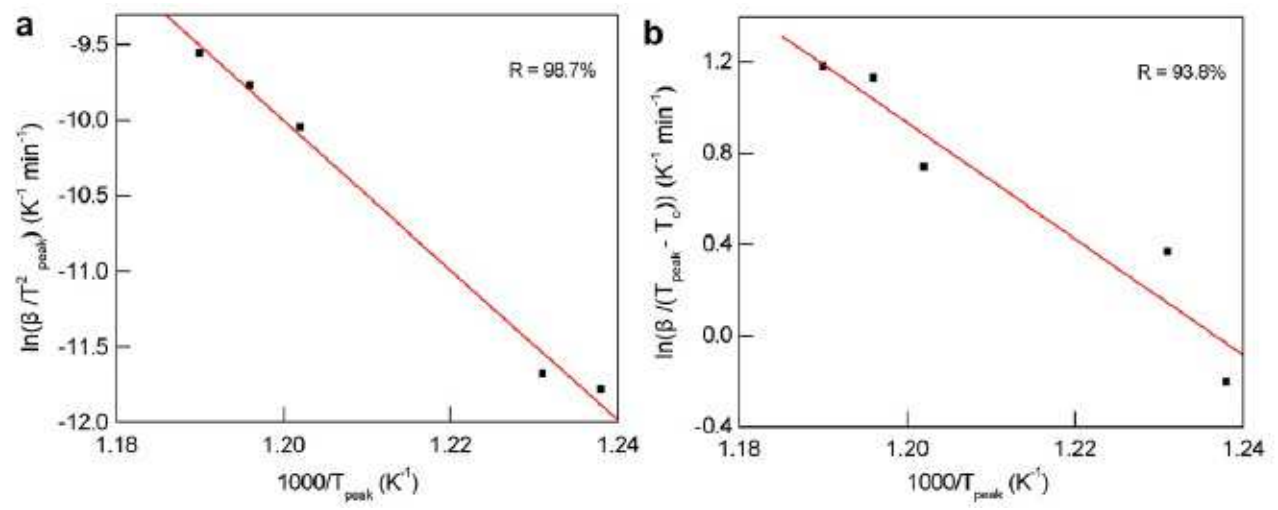

Fig. 28. Plot of the (a) Kissinger and (b) Augis \& Bennett equations for the crystallization in $\mathrm{Ni}_{50.54} \mathrm{Ti}_{49.46}$ thin films (Liu \& Duh, 2007)

The isothermal crystallization kinetics of amorphous materials is described by the JohnsonMehl-Avrami (JMA) equation. The Avrami exponent $\mathrm{n}$ for different temperature ranges from 2.63 to 3.12 between 793 and $823 \mathrm{~K}$ (Fig. 29a), which indicates that the isothermal annealing was governed by diffusion-controlled three-dimensional growth for $\mathrm{Ni}_{50.54} \mathrm{Ti}_{49.46}$
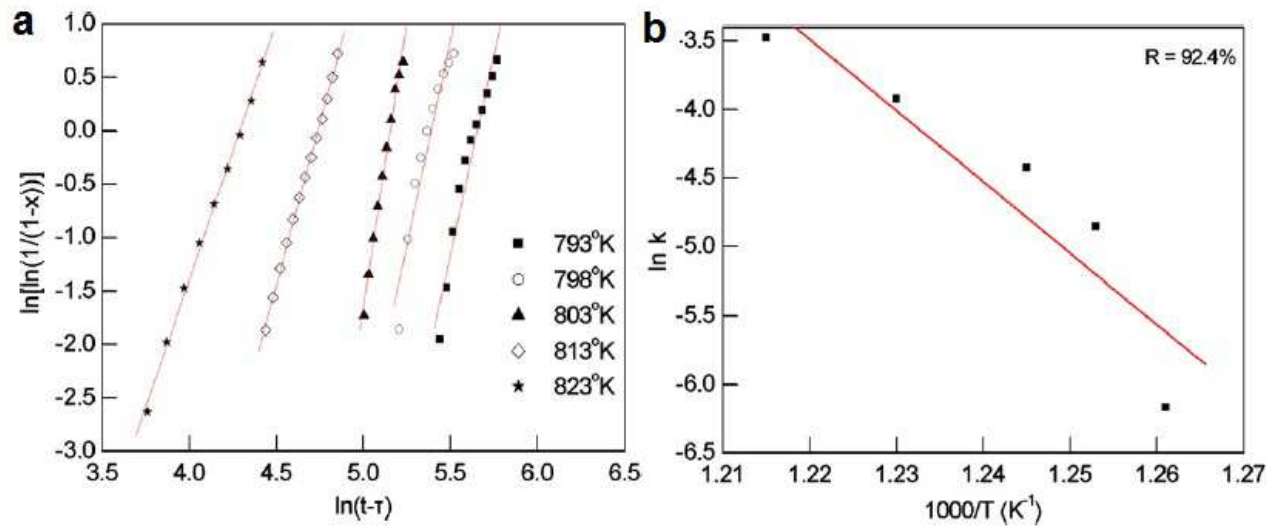

Fig. 29. Plots of the (a) Avrami and (b) Arrhenius equations for the isothermal crystallization of $\mathrm{Ni}_{50.54} \mathrm{Ti}_{49.46}$ thin films(Liu \& Duh, 2007) 
thin films. The $E_{\mathrm{A}}$ value was calculated from the Arrhenius equation and activation energy for crystallization was determined as $424 \mathrm{~kJ} / \mathrm{mol}$ (Fig. 29b). This value is very similar to that from non-isothermal method as determined by the Kissinger analysis $(411 \mathrm{~kJ} / \mathrm{mol})$. It isdemonstrated that the crystallization on both non-isothermal and isothermal methods induces a similar phase transformation mechanism (Liu \& Duh, 2007).

\subsubsection{Amorphous nanomaterials}

The nanocrystallization kinetics of $\mathrm{Ni}_{45} \mathrm{Ti}_{23} \mathrm{Zr}_{15} \mathrm{Si}_{5} \mathrm{Pd}_{12}$ alloy has been investigated using differential scanning calorimetry by means of non-isothermal and isothermal techiques and the products of crystallization have been analyzed by transmission electron microscopy and X-ray diffraction. The bulk amorphous alloy has been prepared by copper mold casting. In the non-isothermal experiments, a set of DSC scans were obtained at a heating rate ranging from 10 to $40 \mathrm{~K} / \mathrm{min}$. For the isothermal analysis, the amorphous samples were first heated to a fixed temperature between 820 and $835 \mathrm{~K}$ at a rate of $200 \mathrm{~K} / \mathrm{min}$, then maintained for a certain period of time until the completion of exothermic process (Qin, 2004).

By using the values of glass transition, $T_{\mathrm{g}}$, crystallization onset, $T_{\mathrm{x}}$, and crystallization peak, $T_{p}$, temperatures a Kissinger plot yields approximate straight lines as shown in Fig. 30. From

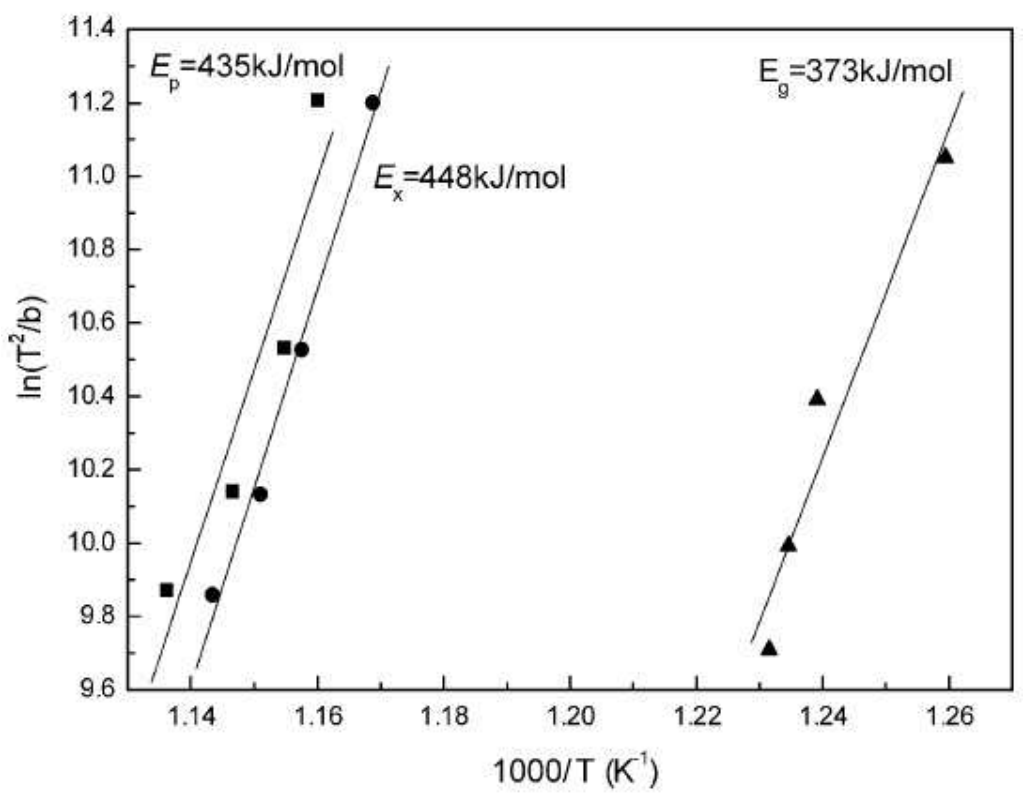

Fig. 30. Kissinger plots of the $\mathrm{Ni}_{45} \mathrm{Ti}_{23} \mathrm{Zr}_{15} \mathrm{Si}_{5} \mathrm{Pd}_{12}$ bulk amourphus alloy (Qin, 2004) 
the slopes of these lines the activation energies were determined as 373,448 and $435 \mathrm{~kJ} / \mathrm{mol}$ for $T_{\mathrm{g}}, T_{\mathrm{x}}, T_{\mathrm{p}}$, respectively. The apparent activation energy $E_{\mathrm{x}}$ deduced from the Kissinger equation for onset crystallization is higher than that for crystallization peak, meaning that nucleation process is more difficult than growth (Qin, 2004).

The bright field TEM image and a corresponding selected area diffraction pattern (SADP) of the bulk specimen after annealing at $840 \mathrm{~K}$ for 900 seconds are shown in Fig. 31. The bright field image shows crystalline nanoparticles embedded in the amorphous matrix. The SADP consists of several ring patterns superimposed on a diffuse halo patterns, also indicating a mixture of nanocrystalline and residual amorphous phase. All the continuous rings can be analyzed into the ordered bcc structure phase with lattice parameter little larger than that of $\mathrm{NiTi}$, which is in agreement with the realized XRD results (Qin, 2004).
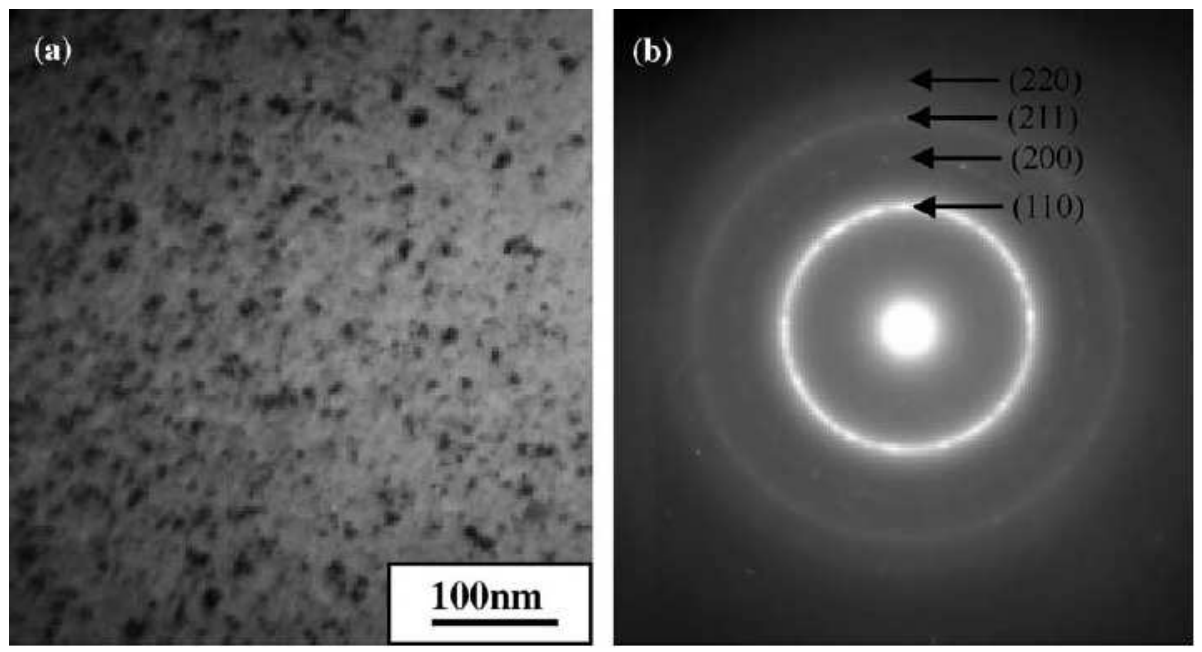

Fig. 31. Bright-field TEM image (a) and selected-are eletron diffraction pattern, (b) of the $\mathrm{Ni}_{45} \mathrm{Ti}_{23} \mathrm{Zr}_{15} \mathrm{Si}_{5} \mathrm{Pd}_{12}$ bulk amourphus alloy annealed for 900 seconds at $840 \mathrm{~K}$ (Qin, 2004)

\section{Conclusion}

In conclusion, crystallization of an amorphous material is a complex phenomenon involving nucleation and growth processes and it can be investigated by taking into account the structure and the kinetics of the crystallization reaction. Crystallization kinetics is crucial since it studies the effect of nucleation and growth rate of the resulting crystalline phase. 
Therefore, this chapter covers the investigation of the crystallization kinetics of amorphous materials by studying the crystallization mechanism in terms of isothermal and nonisothermal methods and describing different thermal analysis techniques used in crystallization kinetic studies and explaining the structural characterization techniques used to determine the crystallization mechanism.

\section{References}

Abdel-Wahaba, F.A., El-Hakim, S.A. \& Kotkat, M.F. (2005). Electrical conductivity and crystallization kinetics of amorphous $\mathrm{Se}_{0.81} \mathrm{In}_{0.19}$ films. Physica B, 366, pp. 38-43, 0921-4526

Abu El-Oyoun, M. (2009). Determination of the crystallization kinetic parameters of $\mathrm{Ge}_{22.5} \mathrm{Te}_{77.5}$ glass using model-free and model-fitting methods. Journal of Alloys and Compounds, 486, pp. 1-8, 0925-8835

Afify, N. (1990). Crystallization kinetics of overlapping phases in $\mathrm{Se}_{0.6} \mathrm{Ge}_{0.2} \mathrm{Sb}_{0.2}$ chalcogenide glass. Journal of Non-Crystalline Solids, 126, pp. 130-140, 0022-3093

Afify, N., Abdel-Rahim, M.A., Abd El-Halim, S. \& Hafiz, M.M. (1991). Kinetics study of nonisothermal crystallization in $\mathrm{Se}_{0.7} \mathrm{Ge}_{0.2} \mathrm{Sb}_{0.1}$ chalcogenide glass. Journal of NonCrystalline Solids, 128, pp. 269-278, 0022-3093

Ahmadi, S., Shahverdi, H.R. \&Saremi, S.S. (2011). Effects of $\mathrm{Nb}$ Alloying on nano-crystallization kinetics of $\quad \mathrm{Fe}_{(55-\mathrm{x})} \mathrm{Cr}_{(18)} \mathrm{Mo}_{(7)} \mathrm{B}_{(16)} \mathrm{C}_{(4)} \mathrm{Nb}_{(\mathrm{x})} \quad(\mathrm{x}=0, \quad 3)$ bulk amorphous alloys. Journal of Materials Science E Technology, 27, pp. 735-740, 10050302

Al-Ghamdi, A.A., Alvi, M.A., Khan, S.A. (2010). Glass transition and crystallization kinetics of $\operatorname{In}_{x}\left(\mathrm{Se}_{0.75} \mathrm{Te}_{0.25}\right)_{100-x}$ chalcogenide glasses. Journal of Alloys and Compounds, 491, pp. 85-91, 0925-8838

Al-Ghamdi, A.A., Alvi, M.A., Khan, S.A. (2011). Non-isothermal crystallization kinetic study on $\mathrm{Ga}_{15} \mathrm{Se}_{85-x} \mathrm{Ag}_{x}$ chalcogenide glasses by using differential scanning calorimetry. Journal of Alloys and Compounds, 509, pp. 2087-2093, 0925-8835

Aly, K.A., Othman, A.A., Abousehly, A.M. (2009). Effect of Te additions on the glass transition and crystallization kinetics of $\left(\mathrm{Sb}_{15} \mathrm{As}_{30} \mathrm{Se}_{55}\right)_{100-} \mathrm{Te} \mathrm{e}_{x}$ amorphous solids. Journal of Alloys and Compounds, 467, pp. 417-423, 0925-8838

Araújo, E.B. \& Idalgo, E. (2009). Non-isothermal studies on crystallization kinetics of tellurite $20 \mathrm{Li}_{2} \mathrm{O}-80 \mathrm{TeO}_{2}$ glass. Journal of Thermal Analysis and Calorimetry, 95, pp. 37$42,1388-6150$

Araujo, E.B., Idalgo, E., Moraes, A.P.A., Souza Filho, A.G. \& Mendes Filho, J. (2009). Crystallization kinetics and thermal properties of $20 \mathrm{Li}_{2} \mathrm{O}-80 \mathrm{TeO}_{2}$ glass. Materials Research Bulletin, 44, pp. 1596-1600, 0025-5408

Avrami, M. (1939). Kinetics of phase change I. Journal of Chemical Physics, 7, pp. 1103-1012, 0021-9606

Avrami, M. (1940). Kinetics of phase change II. Journal of Chemical Physics, 8, pp. 212-224, 0021-9606

Augis, A.J. \& Bennett, J.E. (1978). Calculation of the Avrami parameters for heterogeneous solid state reactions using a modification of the Kissinger method. Journal of Thermal Analysis and Calorimetry, 13, pp. 283-292, 1388-6150 
Bhargava, A., Kalla, J. \& Suthar, B. (2010). Crystallization process in amorphous Sn-Te-Se thin films. Chalcogenide Letters, 7, pp. 175-180, 1584-8663

Carter, C.B. \& Norton, M.G. (2007). Ceramic Materials Science and Engineering, Springer, ISBN10: 0387462708, New York

Chen, J.Z. \& Wu, S.K. (1999). Crystallization behavior of r.f.-sputtered TiNi thin films. Thin Solid Films, 339, pp. 194-199, 0040-6090

Cheng, Y., Xiao, H. \& Guo, W. (2007). Structure and crystallization kinetics of $\mathrm{PbO}-\mathrm{B}_{2} \mathrm{O}_{3}$ glasses. Ceramics International, 33, pp. 1341-1347, 0272-8842

Çelikbilek, M., Ersundu, A.E., Solak, N. \& Aydin, S. (2011). Crystallization kinetics of $\mathrm{TeO}_{2}-$ $\mathrm{WO}_{3}$ glasses. Journal of Non-Crystalline Solids, 357, pp. 88-95, 0022-3093

Çelikbilek, M., Ersundu, A.E., Solak, N. \& Aydin, S. (2011). Investigation on thermal and microstructural characterization of the $\mathrm{TeO}_{2}-\mathrm{WO}_{3}$ system. Journal of Alloys and Compounds, 509, pp. 5646-5654, 0925-8835

Çelikbilek, M., Ersundu, A.E., Solak, N. \& Aydin, S. (2010). Kinetic studies on the tungsten tellurite glasses, ACerS 112th Annual Meeting combined with Materials Science \& Technology 2010 Conference \& Exhibition, Houston, Texas, U.S.A., October 2010

Dahshan, A., Amer, H.H. \& Aly, K.A. (2010). Thermal stability and crystallization kinetics of Ge-Se-Cd glasses. Philosophical Magazine, 90, pp. 1435-1449, 1478-6435

Deepika, Jain, P.K., Rathore, K.S. \& Saxena, N.S. (2009). Structural characterization and phase transformation kinetics of $\mathrm{Se}_{58} \mathrm{Ge}_{42-x} \mathrm{~Pb}_{x}(x=9,12)$ chalcogenide glasses. Journal of Non-Crystalline Solids, 355, pp. 1274-1280, 0022-3093

Doremus, R. H. (1973). Glass science, Wiley, ISBN-10: 0471891746, New York

Elabbar, A.A., Abu El-Oyoun, M., Abu-Sehly, A.A. \& Alamri, S.N. (2008). Crystallization kinetics study of $\mathrm{Pb}_{4.3} \mathrm{Se}_{95.7}$ chalcogenide glass using DSC technique, Journal of Physics and Chemistry of Solids, 69, pp. 2527-2530, 0022-3697

El-Mallawany, R.A.H. (2002). Tellurite Glasses Handbook, CRC Press, ISBN-10: 0849303680, Boca Raton London New York Washington, D.C.

El-Mallawany, R., Abousehly, A., El-Rahamani, A. \& Yousef, E. (1997). Calorimetric study on tellurite glasses. Physica Status Solidi, 163, pp. 377-386, 1862-6319

Ersundu, A.E., Karaduman, G., Çelikbilek, M., Solak, N. \& Aydin, S. (2010). Stability of the $\delta-\mathrm{TeO}_{2}$ phase in the binary and ternary $\mathrm{TeO}_{2}$ glasses. Journal of the European Ceramic Society, 30, pp. 3087-3092, 0955-2219

Ersundu, A.E., Karaduman, G., Çelikbilek, M., Solak, N. \& Aydin, S. (2010). Effect of rareearth dopants on the thermal behavior of tungsten-tellurite glasses. Journal of Alloys and Compounds, 508, pp. 266-272, 0925-8838

Ersundu, A.E., Çelikbilek, M., Solak, N. \& Aydin, S. (2011). Glass formation area and characterization studies in the $\mathrm{CdO}-\mathrm{WO}_{3}-\mathrm{TeO}_{2}$ ternary system. Journal of the European Ceramic Society, 31, pp. 2775-2781, 0955-2219

Gridnev, S.A., Gorshkov, A.G., Sitnikov \& A.V. (2008). The Study of the Isothermal Crystallization and Electrical Properties of Heterogeneous Metal-Ferroelectric Nano-Composites. Ferroelectrics, 374, pp. 194-201, 0015-0193 
Hajiyev, E.S., Madadzadeh, A.I. \& Ismayilov, J.I. (2009). Structure and Kinetics of Crystallization of Thin Amorphous Films of $\mathrm{Yb}_{(1-x)} \mathrm{Sm}_{(x)} \mathrm{As}_{(4)} \mathrm{S}_{(7)}$. Semiconductors, 43, pp. 1492-1495, 1090-6479

Huang, L.J., Li, L., Liang, G.Y., Guo, Y. \& Wu, D.C. (2008). Crystallization kinetics of $\mathrm{Mg}_{65} \mathrm{Cu}_{25} \mathrm{Nd}_{10}$ amorphous alloy. Journal of Non-Crystalline Solids, 354, 1048-1053, 0022-3093

Idalgo, E., Araujo, E.B., Yukimitu, K., Moraes, J.C.S., Reynoso, V.C.S. \& Carvalho, C.L. (2006). Effects of the particle size and nucleation temperature on tellurite 20 $\mathrm{Li}_{2} \mathrm{O}-$ $80 \mathrm{TeO}_{2}$ glass crystallization. Materials Science and Engineering A, 434, pp. 13-18, 0921-5093

Jackson, K.A. (2004). Kinetic Processes: Crystal Growth, Diffusion, and Phase Transitions in Materials, Wiley-VCH, ISBN-10: 3527306943, Weinheim

Jeong, E.D., Bae, J.S., Hong, T.E., Lee, K.T., Ryu, B.K., Komatsu T., \& Kim, H.G. (2007). Thermal properties and crystallization kinetics of tellurium oxide based glasses. Journal of Ceramic Processing Research, 8, pp. 417-420, 1229-9162

Kashchiev, D. (2000). Nucleation, Butterworth Heinemann, ISBN 0750646829, Burlington.

Kalb, J. A. (2009). Crystallization Kinetics, In: Phase Change Materials: Science and Applications, Raoux S., Wuttig M., pp. 125-148, Springer, ISBN: 0387848738, New York

Karaduman, G., Ersundu, A.E., Çelikbilek, M., Solak, N. \& Aydin, S. (2011). Phase equilibria and glass formation studies in the $(1-x) \mathrm{TeO}_{2}-x \mathrm{CdO}(0.05 \leq x \leq 0.33 \mathrm{~mol})$ system. Journal of the European Ceramic Society, 10.1016/j.jeurceramsoc.2011.09.027, 09552219

Kissinger, H.E. (1956). Variation of peak temperature with heating rate in differential thermal analysis. Journal of Research of the National Bureau of Standards, 57, 217-221, 1044-677X

Kissinger, H.E. (1957). Reaction Kinetics in Differential Thermal Analysis. Analitical Chemistry, 29, pp. 1702-1706, 0003-2700

Lei, Y., Zhao, H., Cai, W., An, X. \& Gao, L. (2010). Crystallization kinetics of $\mathrm{Ni}_{x} \mathrm{Ti}_{1-x}$ alloy thin films. Physica B-Condensed Matter, 405, pp. 947-950, 0921-4526

Liu, K.T. \& Duh, J.G. (2007). Kinetics of the crystallization in amorphous NiTi thin films. Journal of Non-Crystalline Solids, 353, 1060-1064, 0022-3093

Malek, J. (2000). Kinetic analysis of crystallization processes in amorphous materials. Thermochimica Acta, 355, pp. 239-253, 0040-6031

Marotta, A., Saiello, S. \& Buri, A. (1983). Remarks on determination of the Avrami exponent by non-isothermal analysis. Journal of Non-Crystalline Solids, 57, pp. 473-475, 00223093

Matusita, K. \& Sakka, S. (1981). Kinetic study on non-isothermal crystallization of glass by thermal analysis. Bulletin of the Institute for Chemical Research, 59, 3, pp. 159-171, 1747-5198

Matusita, K., Komatsu, T. \& Yokota, R. (1984). Kinetics of non-isothermal crystallization process and activation energy for crystal growth in amorphous materials. Journal of Materials Science, 19, pp. 291-296, 0022-2461 
Mehta, N., Kumar, D. \& Kumar, A. (2004). Calorimetric studies of the crystallization growth process in glassy $\mathrm{Se}_{70} \mathrm{Te}_{30-x} \mathrm{Ag}_{x}$ alloys. Turkish Journal of Physics, 28, pp. 396-406, 1300-0101

Mullin, J.W. (2001). Crystallization, Butterworth- Heinemann, ISBN-10: 0750648333, London

Omar, M.A. (1993). Elementary Solid State Physics, Addison-Wesley, ISBN-10: 0201607336,

Ozawa, T. (1971). Kinetics of non-isothermal crystallization. Polymer, 12, pp. 150-158, 00323861

Park, J. (2009). Bioceramics: Properties, Characterizations, and Applications, Spinger, ISBN10: 0387095446, New York

Porter, D.A. \& Easterling, K.E. (1981). Phase Transformations in Metals and Alloys, Chapman \& Hall, ISBN: 0412450305, London, Weinheim, New York, Tokyo, Melbourne, Madras

Prasad, S. \& Varma, K.B.R. (2005). Crystallization kinetics of the $\mathrm{LiBO}_{2}-\mathrm{Nb}_{2} \mathrm{O}_{5}$ glass using differential thermal analysis. Journal of the American Ceramic Society, 88, pp. 357-361, $0002-7820$

Qin, F.X., Zhang, H.F., Ding, B.Z. \& Hu, Z.Q. (2004). Nanocrystallization kinetics of Nibased bulk amorphous alloy. Intermetallics, 12, pp. 1197-1203, 0966-9795

Ragone, D.V. (1994). Thermodynamics of Materials, John Wiley \& Sons.Inc, ISBN10: 0471308854 New York, Chichester, Brisbane, Toronto, Singapore

Ray, C.S., Huang, W.H. \& Day, D.E. (1991). Crystallization kinetics of a lithia-silica glass: Effect of sample characteristics and thermal analysis measurement techniques. Journal of American Ceramic Society, 74, pp. 60-66, 0002-7820

Seeger, C. \& Ryder, P.L. (1994). Kinetics of the crystallization of amorphous Ti-Ni and Ti-Ni-Si alloys, Materials Science and Engineering, A179/A 180, pp. 641-644, 09215093

Shaaban, E.R., Saddeek, Y.B. \& Abdel Rafea, M. (2009). Crystallization kinetics of the $\mathrm{TeO}_{2}-$ $\mathrm{BaO}$ glass system. Philosophical Magazine, 89,pp. 27-39, 1478-6435

Tomasz, C. (2010). Mechanism and kinetics of nano-crystallization of the thermally stable $\mathrm{NiNb}(\mathrm{ZrTi}) \mathrm{Al}$ metallic glasses. Journal of Thermal Analysis and Calorimetry, 101, pp. 615-622, 1388-6150

Yahia, I.S., Shakra, A.M., Fadel, M., Hegab, N.A., Salem, A.M. \& Farid, A.S. (2011). Kinetics of non-isothermal crystallization of ternary $\mathrm{Se}_{85} \mathrm{Te}_{15-x} \mathrm{Sb}_{x}$ glassy alloys. Chalcogenide Letters, 8, pp. 453-467, 1584-8663

Yamane, M. \& Ashara, Y. (2000). Glasses for photonics, Cambridge University Press, ISBN 0511-03862-3, Cambridge, New York, Port Melbourne, Madrid, Cape Town

Yinnon, H. \& Uhlmann, D.R. (1983). Applications of thermoanalytical techniques to the study of crystallization kinetics in glass-forming liquids, Part I: Theory. Journal of Non-Crystalline Solids, 54, pp. 253-275, 0022-3093

Yukimitu, K., Oliveira, R.C., Araujo, E.B., Moraes, J.C.S. \& Avanci, L.H. (2005). DSC studies on crystallization mechanisms of tellurite glasses. Thermochimica Acta, 426, pp. 157$161,0040-6031$ 
Zhang, S.N., Zhu, T.J. \& Zhao, X.B. (2008). Crystallization Kinetics of $\mathrm{Si}_{15} \mathrm{Te}_{85}$ and $\mathrm{Si}_{20} \mathrm{Te}_{80}$ Chalcogenide Glasses. Physica B-Condensed Matter, 403, pp. 3459-3463, 0921-4526 


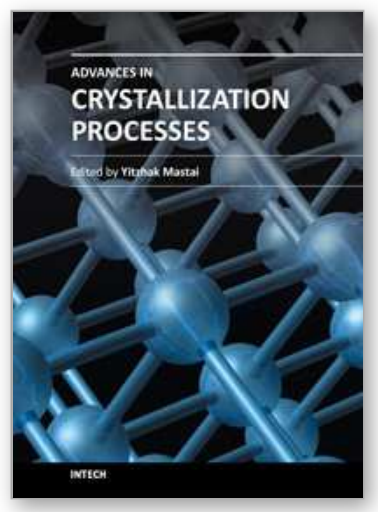

\section{Advances in Crystallization Processes}

Edited by Dr. Yitzhak Mastai

ISBN 978-953-51-0581-7

Hard cover, 648 pages

Publisher InTech

Published online 27, April, 2012

Published in print edition April, 2012

Crystallization is used at some stage in nearly all process industries as a method of production, purification or recovery of solid materials. In recent years, a number of new applications have also come to rely on crystallization processes such as the crystallization of nano and amorphous materials. The articles for this book have been contributed by the most respected researchers in this area and cover the frontier areas of research and developments in crystallization processes. Divided into five parts this book provides the latest research developments in many aspects of crystallization including: chiral crystallization, crystallization of nanomaterials and the crystallization of amorphous and glassy materials. This book is of interest to both fundamental research and also to practicing scientists and will prove invaluable to all chemical engineers and industrial chemists in the process industries as well as crystallization workers and students in industry and academia.

\section{How to reference}

In order to correctly reference this scholarly work, feel free to copy and paste the following:

Miray Çelikbilek, Ali Erçin Ersundu and Süheyla Aydın (2012). Crystallization Kinetics of Amorphous Materials, Advances in Crystallization Processes, Dr. Yitzhak Mastai (Ed.), ISBN: 978-953-51-0581-7, InTech, Available from: http://www.intechopen.com/books/advances-in-crystallization-processes/crystallization-kinetics-ofamorphous-materials

\section{INTECH}

open science | open minds

\section{InTech Europe}

University Campus STeP Ri

Slavka Krautzeka 83/A

51000 Rijeka, Croatia

Phone: +385 (51) 770447

Fax: +385 (51) 686166

www.intechopen.com

\section{InTech China}

Unit 405, Office Block, Hotel Equatorial Shanghai

No.65, Yan An Road (West), Shanghai, 200040, China

中国上海市延安西路65号上海国际贵都大饭店办公楼 405 单元

Phone: +86-21-62489820

Fax: $+86-21-62489821$ 
(C) 2012 The Author(s). Licensee IntechOpen. This is an open access article distributed under the terms of the Creative Commons Attribution 3.0 License, which permits unrestricted use, distribution, and reproduction in any medium, provided the original work is properly cited. 